\title{
How individual needs influence motivation effects: a neuroscientific study on McClelland's need theory
}

\author{
Robert Rybnicek $^{1} \cdot$ Sabine Bergner $^{1} \cdot$ Alfred Gutschelhofer $^{1}$
}

Received: 19 July 2016/Accepted: 13 September 2017/Published online: 12 October 2017

(C) The Author(s) 2017. This article is an open access publication

\begin{abstract}
Among frequently used motivation theories some are built on the premise of work happening in the $60 \mathrm{~s}$ and 70 s. Since work life has changed dramatically the question arises whether these theories are still valid. This study validates the longstanding need theory of McClelland (Am Psychol 40(7):812-825, 1985. doi:10.1037/ 0003-066X.40.7.812) using neuroscientific methods as a new lens of analysis. It neurally tests the assumptions that (1) heterogeneous rewards may result in similarly rewarding effects and (2) that these effects are enhanced if a reward closely matches an employee's need. Therefore, we conducted an fMRI-study ( $n=44 ; 29$; $\mathrm{M}_{\mathrm{age}}=25.00, \mathrm{SD}_{\mathrm{age}}=2.26$ ) in which participants completed decision tasks before receiving the heterogeneous rewards high income, respectful leadership and a company car. Additionally, participants provided information on their need for achievement, affiliation and power. Results show that the heterogeneous types of rewards lead to overlapping neural activations in parts of the brain's reward circuitry, such as the putamen or caudate. Additionally, each of these rewards uniquely activates brain areas not stimulated by other reward types. A closer matching between the type of reward and the participants' individual needs results in stronger neural activations in the reward circuitry. These findings support and enhance key assumptions of need theory on a neural level and further promote a personality-based approach to work motivation. From a practical standpoint they suggest need-tailored reward systems for organizations and an increased use of rewards other than money.
\end{abstract}

Robert Rybnicek

robert.rybnicek@uni-graz.at

1 Department of Corporate Leadership and Entrepreneurship, University of Graz, Elisabethstrasse 50b/2, 8010 Graz, Austria 
Keywords fMRI $\cdot$ Motivation $\cdot$ Need $\cdot$ Reward $\cdot$ Incentive $\cdot$ Motive

JEL Classification M10 - M19 · L20

\section{Introduction}

Motivated employees are considered a key factor in competition, for which reason it is in companies' best interests to motivate their staff. The importance of employee motivation has led to much research devoted to this topic. Despite this effort, Steers et al. (2004) concluded that the research on work motivation has not kept pace with developments in other fields of management and that recent textbooks still rely on theories from the 1960s and 1970s. In spite of these theories' value, it is evident that they are shaped by the understanding of work happening in the 1960s and 1970s. However, work in general and work environments in particular have changed dramatically over the last few decades: increasing diversity, shifting job requirements, new information technologies, innovative forms of organization, changed power distributions and hierarchies as well as increasing globalization are just a few characteristics that describe modern work settings (Steers et al. 2004). Therefore, there is a clear need to carefully consider whether motivation theories commonly used today but rooted in earlier times are still valid. The current study accounts for this requirement and aims at validating a long-standing motivation theory.

In addition to work environments, changes can also be seen regarding the methodological approaches that may be used to validate motivation theory. Contemporary neuroscientific methods provide new possibilities and may help to capture new insights into the question of subconscious motivation processes and the functionality of rewards. They provide a new lens through which one of multiple layers of analysis can be explored (e.g. Cacioppo et al. 2007; Lee and Chamberlain 2007; Ochsner and Lieberman 2001). Adding a neural layer of analysis to existing ones (e.g. social or cognitive layers of motivation theory) may help to establish a more valid and more holistic theory of work motivation. Driven by these advantages, the current study acts on the recommendation to use modern neuroscientific methods for validation purposes (e.g. Locke and Latham 2004).

In our study we draw on McClelland's (1985) need theory. In short, need theory claims that employees are motivated when their need for power, affiliation and achievement are activated. Every employee is particularly motivated by a predominant need and consequently experiences different stimuli as rewarding to a different extent. In that regard, McClelland's (1985) need theory offers both a set of well-defined internal motivation factors (needs) - particularly developed for the workplace - and congruent external motivation factors (rewards; Steers et al. 2004). In light of the new developments regarding work environments and methodological approaches, the overall aim of this study is to validate need theory with neuroscientific methods. To fulfil our aim we focus on two aspects. First, we explore how far distinct management rewards that relate to different McClelland 
(1985) needs result in similarly rewarding effects. Second, we study whether the effect of these distinct rewards is enhanced if they closely match an employee's need.

To approach the study aim with its facets, 44 participants took part in this functional magnetic resonance imaging (fMRI) study. Participants completed decision tasks before receiving either of the three performance-contingent rewards high income, respectful leadership or a prestigious company car. Additionally, they provided information on their need for achievement, affiliation and power. Our findings show that the three different rewards lead to overlapping neural activations in parts of the reward circuitry, such as the putamen or caudate on the one hand, but that these rewards, on the other hand, also activate distinct brain areas that are not stimulated by the remaining two reward types. Furthermore, it is shown that the more a particular reward matches an employee's need the stronger are the neural activations in the reward circuitry.

Our study contributes to the current literature in several ways. First, it offers a neuroscientific perspective to McClelland's (1985) need theory and uniquely validates it by showing that neural reward activations are stronger when a specific reward closely matches the individual need level of a person. Thus, it supports an individual and personality-based approach to work motivation. Second, this study contributes to neuroscience as it enhances our understanding of different rewards and their location in the reward circuitry by investigating rewards that are commonly used in the management context and that have not been studied before. Moreover, it supports the idea of a mutual 'reward system' on the one hand and reward type-dependent brain structures on the other hand (Sescousse et al. 2013b). Finally, this study provides insights into subconscious processes of motivation and, therefore, it can be regarded as a step towards a boundaryless science of work motivation, as suggested by Locke and Latham (2004). The practical implications we draw from our results refer to an individual approach to work motivation in which the varying needs of employees have to be adequately considered.

In the following section, a theoretical background on work motivation and corresponding neurological findings is provided before the hypotheses are derived. Following this, the methodological approach and the results are presented before discussing them with respect to their implications.

\section{Theoretical background and hypotheses development}

Motivation is considered a key driver of performance because it is linked to numerous benefits at work (Campbell and Pritchard 1976; Maier 1955; Pinder 2008). Motivated employees are more engaged in their work (Rich 2006), their performance is of higher quality (Cerasoli et al. 2014) and they profit more from occupational training (Massenberg et al. 2015). Additionally, they are more strongly committed to their work, work longer hours, pick more challenging goals to achieve (Becker et al. 2015), and are more willing to share knowledge at the workplace (Lin 
2007). Due to its positive consequences, motivation plays a central role in the field of management, both in theory and management practice.

\subsection{Work motivation and its behavioural background}

Work motivation refers to factors that energize, direct and maintain employee behaviour over time (Steers et al. 2004). In their overview, Steers et al. (2004) and Latham and Pinder (2005) summarize three major directions of motivation theory: first, content theories aim at identifying factors positively associated with motivation. Major content theories include, for instance, Maslow's (1943) theory of hierarchical needs, Herzberg et al.'s (1959) motivator-hygiene theory, and McClelland's (1987) need theory. Second, process theories focus on the processes underlying work motivation and regard motivation from a dynamic perspective. Some of the most prominent process theories are, for instance, goal-setting theory (Locke and Latham 2002), social-cognition theory (Bandura 1977), or expectancy theory (Vroom 1964). Third, justice theories add a sociological perspective to work motivation with the premise that fair procedures in an organizational context enhance motivation (Latham and Pinder 2005).

Although an exact understanding of motivation continues to evolve, most theoretical approaches argue that motivation emerges from both internal factors of an individual that drive action and external factors of the environment that stimulate action (Locke and Latham 2004). This also applies to McClelland's (1987) theory of needs, an approach that is considered a content theory of motivation. In essence, McClelland's (1987) theory of needs suggests that each employee has several, often competing needs and that motivation of employees results from their attempt to fulfil these needs. Ideally, the work environment offers external factors (e.g. rewards) that promise need-fulfilment. In other words, when external factors (rewards) interact with internal factors (needs) work motivation is observed (Beckmann and Heckhausen 2008; Schneider and Schmalt 2000).

\subsubsection{Needs as internal factors}

Needs refer to an internal tension that influences the cognitive processes which underlie behaviours (Kanfer 1991). Within the management context three needs are of specific importance (McClelland and Burnham 2008): (1) the need for achievement; (2) the need for affiliation; and (3) the need for power. According to McClelland (1985), employees differ regarding their levels of needs. The need for achievement is defined by a preference for achieving excellence in accomplishments through one's individual efforts (McClelland et al. 1953). Persons high in this need dimension show a stronger desire to perform at a more advanced level than their peers. They dislike succeeding only by chance and prefer personally identifiable reasons for their success rather than leaving the outcome to probability. Furthermore, persons with a high need for achievement are regarded as more effective leaders and are more satisfied in jobs that are challenging and that demand a high skill level (Eisenberger et al. 2005; McNeese-Smith 1999). The need for affiliation refers to the concern for establishing and maintaining close personal 
relationships with others (e.g. supervisors, colleagues). It is furthermore represented by a desire to participate in cooperative and interactive activities (McClelland 1976). Those with higher needs for affiliation also receive better leadership ratings (Jeffrey 2009) and show more identification with the organization (Wiesenfeld et al. 2001). Finally, the need for power describes the concern for impact and prestige, which is associated with getting formal social power and taking risks (Winter and Stewart 1978). Persons with high power needs prefer being in competitive, statusdriven situations and actively seek to gather symbols of status (Veroff 1992). They report higher job tension (Lilly et al. 2006) and tend to be entrusted with resources that are perceived as valuable (Magee and Galinsky 2008; Thye 2000). Concerning the current study, it is important that employees differ regarding the level of their need for achievement, affiliation and power.

\subsubsection{Rewards as external factors}

External factors of work motivation refer to stimuli provided by an organizational environment that encourage action (Cerasoli et al. 2014). External factors are termed differently, depending on the chosen theory, scientific field and research method. Meta-analyses on work motivation commonly refer to external factors as rewards, incentives, reinforcements or extrinsic motivation (e.g. Deci et al. 1999). However, neurophysiological studies most frequently use the term rewards for which reason we subsequently also use this term (see e.g. Sescousse et al. 2013b). Money might be the most commonly used reward in organizations (Pinder 2008). However, many other rewards, such as promotions, awards, company cars, health benefits or social recognition, can be listed. When classifying organizational rewards, von Rosenstiel (1975) summarized the following five categories: (1) 'direct financial rewards' such as pay-for-performance systems, (2) 'indirect financial rewards' including, for example, free access to a company car or a work mobile phone, (3) 'organizational rewards' referring to aspects like leadership style or size of organization, (4) 'social rewards' like information distribution and communication style when interacting with others and (5) 'work rewards' which denote work characteristics such as autonomy and possible career advancement. Empirical evidence clearly supports the use of direct and indirect financial rewards to enhance employee performance. For instance, providing financial reward increases the quality and quantity of employee performance and further leads to more creativity at work (e.g., Byron and Khazanchi 2012; Condly et al. 2003; Jenkins et al. 1998). More recently, Cerasoli et al. (2014) showed that (direct and indirect) financial rewards impact performance quantity much stronger than performance quality. Thus, regarding the current study it is important to note that there are different reward categories and that there is empirical evidence that when organizations offer financial rewards, their employees' performance is likely to improve. However, there seems to be a shortcoming of research regarding non-financial rewards, even though organizations continue to implement these (de Gieter and Hofmans 2015). 


\subsubsection{Interaction between rewards as external and needs as internal motivation factors}

As mentioned earlier, work motivation results from the interaction of an employee's needs and organizational rewards. According to McClelland (1985), when an employee's need is strong it stimulates those behaviours that lead to needfulfilment. Therefore, if an organization wants to direct employee behaviour it should offer rewards that promise need-fulfilment. Meta-analytic findings support the interaction of internal factors of motivation and financial rewards as external factors. Cerasoli et al. (2014) summarized that both internal as well as external factors (i.e. financial reward) contribute to performance. Similarly, a study by Hendijani et al. (2016) demonstrated that a financial bonus as external factor and a personal interest as internal factor of motivation conjointly contribute to the motivation of study participants. To sum up, evidence indicates that external factors of motivation have to be considered conjointly with internal ones when understanding motivation-driven performance. At this point it shall be considered that the conjoined consideration has been mainly investigated with respect to financial rewards. This study extends previous findings and further examines the interaction of external and internal factors with regard to non-financial rewards.

\subsection{Neurophysiological background}

Motivation is closely linked to the neurotransmitter dopamine and the dopaminergic reward system. This reward system is a network of neurons that communicate through the neurotransmitter dopamine. When exposed to rewards, the brain responds by increasing its activity. It sends a signal announcing this reward to a particular part of the midbrain, the ventral tegmental area (VTA). The VTA then releases the neurotransmitter dopamine into the nucleus accumbens (NAcc), but also into the septum, the amygdala and the prefrontal cortex. These regions are connected by a so-called pleasure or reward bundle often referred to as 'reward circuitry'. This reward circuitry is said to supply most of the necessary motivation of human behaviour. Importantly, it is the neural circuit of interest in this study as it responds to rewards (for further information on the reward circuitry see Haber and Knutson 2010).

A particularly critical component of the reward circuitry is the striatum. The striatum is a subcortical structure of the forebrain that is often divided into a dorsal (describing an upper section of the brain) and a ventral (describing a lower brain section) part. The dorsal striatum contains the caudate nucleus and putamen, while the ventral striatum contains the NAcc. Functionally, the striatum coordinates multiple aspects of cognition, including reward perception, motivation, reinforcement learning or voluntary movement (Haber and Knutson 2010).

Neuroimaging studies have demonstrated that the striatum is activated by a large spectrum of different rewards. For example, Spreckelmeyer et al. (2009) reported that monetary gain in a decision task and smiling faces representing social reward lead to activations in the striatum, especially in the NAcc. Kohls et al. (2013) found activations in the NAcc, caudate nucleus and putamen when social approval was 
anticipated, whereas Mitterschiffthaler et al. (2007) reported increased activation in the ventral and dorsal striatum when listening to cheering music like Strauß's 'Radetzky March'. More recently, Lacey et al. (2011) even showed that artistic photographs activate the ventral striatum, and also imagining eating chocolate increases brain activation in the aforementioned areas (Small et al. 2001). Enhanced activation in the caudate nucleus, putamen and the NAcc were further related to many other rewards, such as erotic films (Karama et al. 2002), pictures of highcalorie-food in obese people (Rothemund et al. 2007), pictures of one's own children (Leibenluft et al. 2004), or photos of alcoholic drinks presented to alcoholics (Braus et al. 2001).

Taken together, the ventral and dorsal striatum are key structures in the reward circuit. As suggested by the findings above, they are involved in processing a wide variety of rewards. In fact, meta-analyses of neural studies on rewards suggest that the striatum is activated by rewards irrespective of their modality (e.g. Sescousse et al. 2013b). Thus, it is also considered a reward modality-independent brain structure. Additionally, however, rewards have been shown to activate areas dependent on their modality, for which reason reward modality-dependent brain structures are described. With regard to such modality-dependence it has been described that the amygdala was more robustly activated by, for instance, erotic rewards versus money or food rewards. Similarly, specific parts of the insula were more likely to be triggered by food rewards compared to money and erotic rewards (Sescousse et al. 2013b).

Despite these findings it is important to keep in mind that except for money, neural studies on rewards rarely include rewards that are relevant to the management context. This study takes a step toward closing this gap as it solely examines rewards commonly used in management.

\subsection{Aim and hypotheses of this study}

The overall aim of this study is to validate McClelland's (1985) need theory using neuroscientific methods and thereby fostering foundations of work motivation. To fulfil this aim two hypotheses are derived. First, we examine how far different management rewards are perceived as comparably rewarding. By doing so McClelland's core assumption that different external motivation factors may contribute to work motivation will be validated. Investigating this matter further provides a neural basis for our second hypothesis, examining whether this neural basis changes once individual needs are considered.

In this study, the following three contemporary management rewards are represented: (1) high income, (2) respectful leadership and (3) prestigious company cars. According to von Rosenstiel (1975), these rewards represent the reward categories 'direct financial rewards', 'organizational rewards' and 'indirect financial rewards', respectively. As behavioural results suggest that motivation triggered by both, financial and non-financial rewards increases performance-assuming that these rewards have a comparable rewarding effect (Cerasoli et al. 2014) - it is expected that rewards representing three different reward categories show effects that overlap to a certain extent. However, since Cerasoli et al. (2014) additionally 
demonstrate that motivation triggered by financial and non-financial rewards differently impacts the quality and quantity of performance, it is further expected that there is also a unique effect tied to rewards from different reward categories. The latter expectation is further supported by findings from de Gieter and Hofmans (2015), who show that there are differences in the effects of financial, material and psychological rewards.

As outlined in the previous section neural findings support the assumption that different rewards have both, overlapping and specific effects. In fact, neural findings show that different rewards, such as food, money or erotic pictures, activate reward modality-independent brain areas, yet they also depict reward modality-dependent activations. Combining behavioural and neural findings and further building on Sescousse et al. (2013b) and Kohls et al. (2013), we assume that there is a substantial overlap in the ventral and dorsal striatum, which represent the modalityindependent reward areas, when experiencing high income, respectful leadership and prestigious company cars. However, also in line with behavioural results and also building upon Sescousse et al. (2013b) and Kohls et al. (2013) we further argue that these three rewards too depict modality-dependent activation patterns that are not shared with other rewards. Concluding, the following hypothesis is stated:

H1 The rewards high income, respectful leadership and prestigious company cars share a common neural basis in the striatum and further show reward modalitydependent activation patterns.

The second hypothesis refers to empirical findings suggesting that work motivation is based on an interaction of needs (internal factors) and rewards (external factors; e.g. Cerasoli et al. 2014). Building on these findings we test a key assumption of the need theory and examine on a neural level whether a closer match between an employee's needs and the rewards that offer need fulfilment result in more rewarding effects. According to McClelland's (1985) need theory, higher work motivation should be observed when a reward meets a corresponding need. Initial findings support this assumption, yet primarily for rewards outside the management context. For instance, when rewards match a person's need level then this person experiences more positive affect (Brunstein et al. 1998), refers to fewer psychosomatic complaints (Baumann et al. 2005), and reports an increased feeling of flow (Schüler and Brandstätter 2013). Moreover, need-reward match affects the budget goal commitment of managers (Sandalgaard et al. 2011) and enhances trust as well as trustworthiness (Fehr and List 2004). Since the benefits of a high match between a person's needs and the rewards presented by an environment relate to higher brain activations of the reward circuitry (primarily the striatal area), the following hypothesis is stated:

H2 Rewards that closely match an employee's need result in stronger neural activations of the reward circuitry than rewards that match this need to a lesser extent. 


\section{Method}

\subsection{Sample}

In total, 44 (29 females) healthy MBA students with a mean age of 25 years $(S D=2.26)$ participated in this study. Because handedness, vision, and neurological illness may systematically impact brain activations (e.g. Knecht et al. 2000), all students were right-handed, with normal or corrected-to-normal vision and not a single person reported a history of neurological illness. Participants were screened for exclusion criteria (e.g. metal in the body, physical impairment, pregnancy, psychosis) and all provided written informed consent as part of the university's ethics committee protocol.

Contrary to the usual practice in experimental economics, the study presented in this paper was not incentivized in the sense that the compensation of subjects depended on their decisions in the experiment. Instead we followed the common neuroscientific conventions of paying a fixed compensation to the participants ( $€$ 15). This decision was necessary, because we could have only made a monetary compensation for the money treatment, as it would not have been possible to provide an actual company car or a respectful leader as a reward in the other treatments. As incentivizing only the money treatment while using hypothetical rewards in the other two treatments would have introduced a potential confounder, we implemented all three rewards hypothetically. Nevertheless, we consider this as a potential limitation and we refer to it in the Limitation section.

\subsection{Study design}

The study consisted of two main parts: (1) a pre-scanning part and (2) a scanning part. At the beginning of the pre-scanning part participants were told a cover story to help them establish an employee role. As is common in neuroscientific experiments, the cover story was approved by the university's ethical protocol. They were told that they had the chance for an internship and that depending on their task performance in the MR-scanner they would be compensated with different rewards in the internship. In the pre-scanning part, participants also received information about the task they had to complete in the scanner-which in fact was only a distraction task-and about the hypothetical rewards they could receive. The distraction task and the rewards are described in Sects. 3.2.1 and 3.2.2, respectively.

In the scanning part, an experiment with four different treatments (i.e. three reward treatments and one control treatment) was performed. An event-related fMRI-design ${ }^{1}$ was conducted for all four treatments to account for the neural response to every single reward and to the control treatment. In each treatment, participants followed the exact same procedure. The MRI procedure is described in Sect. 3.2.4 in more detail.

\footnotetext{
1 Event-related fMRI-designs make it possible to associate brain processes with a single stimulus (in contrast to block designs) and thus offer more flexibility for the way to set up experiments.
} 


\subsubsection{Distraction task}

Commonly, in a management environment rewards are provided when tasks have been successfully completed or goals have been met. Thus, a task was needed in this study to justify the giving of rewards. This task was a comparison task where participants had to decide in which of two dot-filled circles there were more dots. For detailed task descriptions of this non-symbolic magnitude comparison task see the MRI procedure below and also Costa et al. (2011) and Dehaene et al. (2005). However, as the focus of this study was on the neural response to rewards, the task was primarily a distraction task to evoke a certain effort in the study participants that should resemble the working effort of an employee. Thus, the distraction task was necessary to create a reliable performance-related situation where participants could be compensated with management-related rewards. For motivational reasons the task was manipulated so that every single participant completed $60 \%$ of the tasks correctly. Within this study there was in fact no interest in the task performance of the participants.

\subsubsection{Rewards}

With respect to the theoretical background of our literature review, three reward treatments and one control treatment were provided. Each of the three rewards primarily addressed another need. All rewards were introduced to the participants in the pre-scanning part of this study. According to the cover story, the more distraction tasks a participant solved correctly in the MR-scanner the higher was his/ her chance for (a) a high income in the internship, (b) a prestigious company car, and (c) a respectful leader. In contrast, the more distraction tasks the participant solved incorrectly the higher was his/her chance for (a) a low income in the internship, (b) a low-prestige company car, and (c) an impersonal leader.

- Money treatment Study participants simultaneously saw two pictures in the MRscanner after completing a task, one representing a high income (a bundle of banknotes; Money+) and one representing a low income (a few coins; Money-). Whenever they solved a single task correctly the picture of the bundle of banknotes was framed with a green frame and their chance of getting a high income rose. Conversely, whenever they solved a single task incorrectly the picture of the few coins was framed and their chance of getting a low income rose.

- Car treatment In the pre-scanning part participants were introduced to ten company cars of varying prestige (e.g. BMW, Audi, Hyundai, Kia). They individually ranked the cars according to prestige and social status. In addition, a recent newspaper article about the importance of cars as status symbols was presented. Following the logic of the money treatment, participants simultaneously saw two pictures in the MR-scanner after completing a task, one represented a car they had rated high regarding prestige and social status (e.g. BMW; Car+) and another picture showing a car, which they had rated low in terms of prestige and social status (e.g., Hyundai; Car-). Whenever they solved 
a single task correctly the prestigious car was framed with a green frame and their chance for a prestigious company car rose. Conversely, whenever they solved a single task incorrectly the picture of the less prestigious company car was framed and their chance for a company car with low prestige rose.

- Leadership treatment In the pre-scanning session participants were introduced to two leaders and to their way of leading employees. They listened to a meeting that was held by the leaders at the beginning of a new project (each leader held one meeting). Thereafter, they evaluated the leadership style on a questionnaire and rated how much each leader respected, motivated, valued and inspired his employees.

Following the logic of the car and money treatment, participants simultaneously saw two pictures in the MR-scanner after completing a task, whereby one leader represented the respectful leader (Leader+) and the other represented the impersonal leader (Leader-). Whenever participants solved a single task correctly the respectful leader was framed with a green frame and their chance of working for a respectful leader increased. Conversely, whenever they solved a single task incorrectly the picture of the impersonal leader was framed and their chance of working for the impersonal leader rose.

Study participants did not know that both leaders were fictional characters. The pictures of the leaders were randomly chosen from the Neutralized Faces Database (Ebner 2008). The speeches of the leaders were derived from Kirkpatrick and Locke's (1996) experimental study on leadership behaviour. A number of studies have demonstrated that one of those speeches represented a cherishing leadership style where followers were respected, motivated, valued and inspired, while the other speech represented an impersonal leadership style where followers were not approached or respected in a personal way and where the leader acted in a detached way (see, for instance, Felfe and Schyns 2006). The speeches were recorded by two professional announcers. The pairing of the announcers and leaders as well as the introduction to each leader and the pairing of the pictures and leaders was randomized across participants.

- Control treatment A control treatment was needed to control for the brain activity that occurred solely because participants answered the distraction task correctly. In order to achieve this, the brain activity of the control treatment was subtracted from the brain activity that occurred in each reward treatment. Thus, only the reward-specific brain activity remained. In this control treatment an upward-facing arrow (Arrow+) was shown whenever the participants answered a distraction task correctly. In contrast, a downward facing arrow (Arrow-) was shown whenever the participants answered a distraction task incorrectly.

\subsubsection{Matching of needs and rewards}

In the course of this study each of the three rewards was investigated conjointly with those of McClelland's (1985) needs that it matched closest. This was done to examine whether rewards that closely correspond with an employee's need result in stronger neural activations of the reward circuitry (hypothesis 2). The rewards were 
presented using the reward treatments and the three needs were measured using the Personal Values Questionnaire (PVQ; McClelland 1991) described in the section Behavioural measures.

Table 1 summarizes empirical findings that indicate that each of the rewards of this study most strongly correlates with one particular need. In line with McClelland (1985), it is argued that individuals differ regarding their predominant need. As needs are expressed through behaviours, choices or personal characteristics, different predominant needs are expressed through differences in behaviours, choices or personal characteristics. The stronger a certain reward reflects the behaviours, choices or personal characteristics tied to a need, the closer will be the match between this need and the reward (see Table 1).

With respect to the achievement need, empirical findings suggest that it best matches the reward high income because individuals who have a higher need for achievement also value money/income to a higher extent (Kirkcaldy and Furnham 1993; Tang 1995). In addition to this direct link between high income and the achievement need, findings also indicate a number of corresponding preferences, individual characteristics and behaviours that are expressed by individuals with both a high need for achievement and a distinct appraisal of money/income. For instance, individuals who strongly value money also score more highly with regard to competitiveness and self-confidence (Kirkcaldy and Furnham 1993; Wong and Carducci 1991), just like individuals with a high need for achievement (Houston et al. 2002; McClelland and Steele 1973). Moreover, persons who highly value money are more conscientious and show more Type A behaviour (Boyce and Wood 2011; Tang 1995) and are therefore similar to those with a high need for achievement (Kern and Friedman 2008; Spence et al. 1989). In conclusion, a direct need for the achievement-money link and several parallels between individuals who score highly on the achievement need and the appraisal of money suggests that the achievement need very closely matches the reward high income.

Regarding the affiliation need, it is argued that this particular need most closely relates to the reward respectful leadership. Empirical findings support this assumption as they show that employees with a higher need for affiliation feel better supported by their leader and show more emotional attachment as well as trust and warmth (Engeser and Langens 2010; Lewis 2000; Wiesenfeld et al. 2001). Similarily, employees of respectful leaders also report higher support from their leaders, are also more emotionally attached and experience more trust (Boezeman and Ellemers 2007; Braun et al. 2013; Kellett et al. 2002). Moreover, individuals with a higher need for affiliation also identify more strongly with their organization and describe themselves as more extraverted (Engeser and Langens 2010; Wiesenfeld et al. 2001), just like individuals who experience respectful leadership (Boezeman and Ellemers 2014; Felfe and Schyns 2006). In conclusion, findings suggest that the affiliation need most closely matches the reward respectful leadership as there are several parallels between individuals with both, a high affiliation need and personal experience with respectful leaders.

With respect to the need for power, findings suggest that this most closely matches the reward prestigious company car-representing a prestigious object. In fact, individuals with a high power need invest in status enhancement despite severe costs because of how highly they value prestige (Winter 1973), and thus behave in a very 


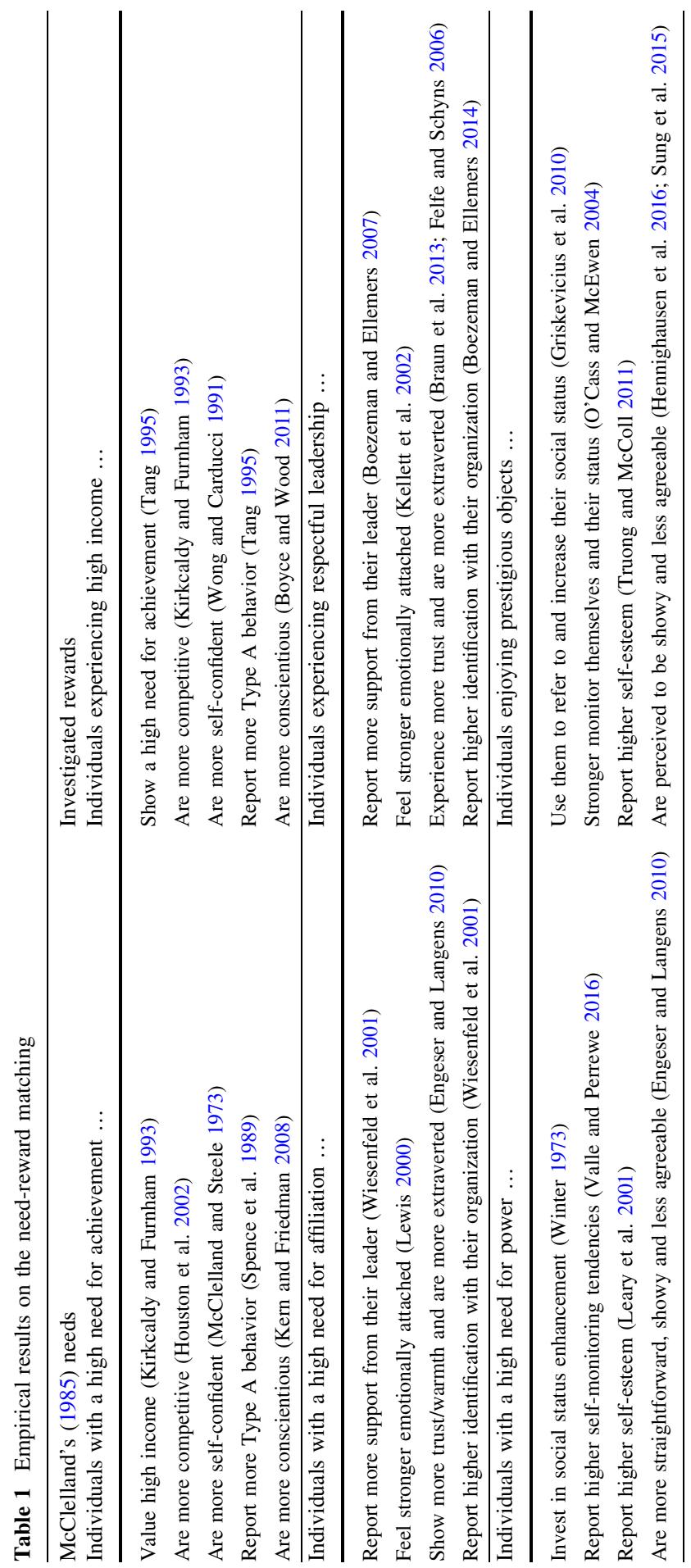




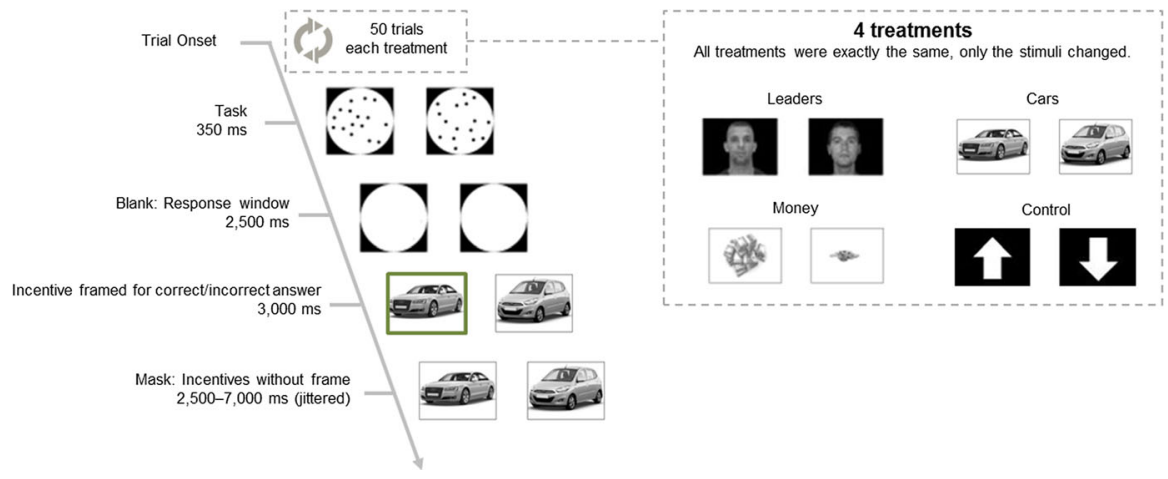

Fig. 1 MRI-procedure

similar manner as those investing in a prestigious car (Griskevicius et al. 2010). Additionally, persons who are driven by a need for power strongly monitor themselves and their appearance and further report higher self-esteem (Leary et al. 2001; Valle and Perrewe 2016). The very same behaviour tendencies are linked to those who enjoy possessing prestigious objects like, for instance, cars (O'Cass and McEwen 2004; Truong and McColl 2011). To add another conjoining aspect, those with a strong power need are seen as showy, boastful and less agreeable (Engeser and Langens 2010) and are therefore similarly perceived as individuals who strongly value prestigious objects (Hennighausen et al. 2016; Sung et al. 2015). Based on the findings supporting a strong link between the need for power and prestigious objects, the power need is perceived to strongly match the reward prestigious company car.

\subsubsection{MRI-procedure}

In the scanning part of the experiment, an event-related design was conducted with three reward treatments and one control treatment, whereby all participants had to complete all reward treatments as well as the control treatment (i.e. a within-subject design was used). In every single treatment (money, cars, leaders and control) participants had to complete 50 of the trials subsequently described. Treatments were presented in randomized order to all participants. After study participants had completed the 50 trials of a single treatment, the trials of the next treatment started. All treatments were exactly the same and only the rewards changed.

As depicted in Fig. 1, a single trial began with the distraction task (i.e. the comparison task described above). In this task, participants were asked to decide in which of two circles there were more dots. To this end, two circles with dots were displayed for $350 \mathrm{~ms}$. Then the dots disappeared, and the white-filled circles remained empty. In the subsequent $2500 \mathrm{~ms}$ time, participants had to indicate whether there were more dots in the left or right circle. Participants responded by either pressing a button for the left or the right circle.

If the task was solved correctly, the particular reward of each treatment (i.e. the picture for a high income, prestigious car, respectful leader, upward arrow) was framed for $3000 \mathrm{~ms}$. If the task was solved incorrectly, the opposing picture was 
framed for $3000 \mathrm{~ms}$. If participants did not respond to the task within $2500 \mathrm{~ms}$ then both pictures for a reward (e.g. high and low amount of money) were framed with a green frame. The framing then disappeared and the rewards remained on the screen for systematically varying periods of time (i.e. the rewards remained on the screen jittered in time with inter-trial intervals from 2500 to $7000 \mathrm{~ms}$ ). To increase the salience of a particular reward, participants were instructed to imagine what feelings would arise when they received that particular reward in their internship.

\subsection{Measures}

This section provides an overview of the behavioural questionnaires used and gives information on the MRI-data acquisition and data analysis. Since information on the acquisition and analysis may sound very technical to readers less familiar with neuroscientific experiments, it is split. First, to make MRI-data acquisition and data analysis available for a larger readership, information on those two issues is presented in a broader sense where background information is added to make the technical information more accessible. Second, the "Appendix" offers additional technical details and displays information on the data acquisition and data analysis in a way that is commonly used when reporting to a readership highly familiar with MRI studies.

\subsubsection{Behavioural measures}

3.3.1.1 Needs Needs had to be measured in order to study whether rewards that closely match an employee's needs result in stronger neural activations of the reward circuitry than rewards that match those needs to a lesser extent. The need for achievement, affiliation and power were measured with the Personal Values Questionnaire (PVQ; McClelland 1991). Each need was operationalized by 10 items that are answered on a five-point Likert scale ranging from (1) 'strongly disagree' to (5) 'strongly agree'. Items regarding the need for power refer to the wish to hold high-status positions, lead others and to be prestigious. The need for achievement is measured with items concerning the development of one's own competencies in solving difficult problems and a preference for taking responsibility for achievement projects. The need for affiliation is assessed by items that represent the wish to be with others or to interact with others in a friendly manner.

Studies on the psychometric qualities of the PVQ (e.g. Brunstein and Hoyer 2002) indicate good reliability and validity. Supporting its construct validity, studies show strong intercorrelations with other need measurements (e.g. Schönbrodt and Gerstenberg 2012 or Bilsky and Schwartz 2008) and further show concurrent findings with neurophysiological need measurement (Dufner et al. 2015; Quirin et al. 2013). Based on these validation results it may be concluded that the PVQ's construct validity is strongly supported. Similarly, its criterion validity is also supported by various studies (e.g. regarding life-satisfaction and emotional wellbeing in Hofer and Chasiotis 2003 or cultural values of supply chain managers in Sharif and Irani 2012). 
3.3.1.2 Respectful leadership To verify whether differences in leadership behaviour could be noticed, participants rated the two leaders regarding their leadership behaviour at the end of the pre-scanning session. To this end, the scale 'individual consideration' of a translated version (Felfe and Goihl 2002) of the Multifactor Leadership Questionnaire (MLQ; Bass and Avolio 1995) was administered to measure how respectful the leadership behaviour was perceived to be by study participants. The four items were completed on a five-point Likert scale ranging from 'do not agree at all' (1) to 'totally agree' (5). The ratings were provided separately for the respectful leader (Leader+) and the non-respectful leader (Leader-). For Leader+ the Cronbach Alpha value was .82 and for Leaderthe internal consistency was .84. A $t$ test showed that the respectful leader (Leader+) received significantly higher ratings on the scale 'individual consideration' than the impersonal leader $\left(t_{42}=21.23, p<.01, \quad \mathrm{M}_{\text {Leader+ }}=4.48\right.$, $\mathrm{SD}_{\text {Leader+ }}=.38$ vs. $\mathrm{M}_{\text {Leader- }}=1.31, \mathrm{SD}_{\text {Leader- }}=.40$ ).

\subsubsection{MRI data acquisition}

In order to gather information on the participants' brain activations, an fMRIexperiment was conducted. Participants were asked to lie down on a platform next to the MR-scanner before their head was put into a head coil. The head coil is necessary to collect coronal image slices and thus imaging the entire brain is possible. It is further used to fixate the head of the participants to minimize head movement, since head movements are regarded as artefacts in MRI experiments. Once the participants were instructed and placed on the platform, the platform was moved into the centre of the MR-scanner. Participants were able to see outside of the scanner by looking at a mirror, which was mounted on the head coil. Outside of the scanner there was a screen on to which all visual stimuli (e.g. pictures of the rewards) were projected.

Once the experiment started the participants' brain was scanned and images of the brain were recorded. Thus, the primary data were time series of images. In this study the blood-oxygen-level-dependent (BOLD) signal was used to measure neural activity. The basic idea of the BOLD signal can be summarized as follows: when a brain area is more active it consumes more oxygen and to meet this increased demand, blood flow increases to the activated area. Oxygenated blood has different magnetic characteristics from deoxygenated blood (Pauling and Coryell 1936). The BOLD signal works by detecting the changes in blood oxygenation and blood flow that occur in response to neural activity. It therefore allows conclusions to be drawn on whether a particular brain area contributes to a particular mental process. (For a more comprehensive description of the BOLD signal see Ashby 2011.)

All visual stimuli were presented using the software package Presentation 16.0 (Neurobehavioral Systems, Albany, CA, USA) and projected on a semi-translucent screen positioned approximately $1.5 \mathrm{~m}$ in front of the scanner. Imaging was done on a 3.0T Magnetom Skyra (Siemens Medical Systems, Erlangen, Germany) using a 32-channel head coil. For more technical information on the MR-scanner and on the process of imaging (e.g. field strength, number of volumes, pulse sequence type, 
slice thickness, TE/TR/flip angle, order and orientation of acquisition) please see the information provided in "Appendix".

\subsubsection{MRI data analysis}

In this study MRI data analysis was conducted in four steps. The first step of the analysis comprised preprocessing activities where systematic non-task-related sources of variability were removed from the imaging data (e.g. artefacts due to head movement or high-frequency spatial noise resulting from the digitization of the imaging). Second, the time series analyses on each participant's data were carried out (i.e. first-level analyses). As is common for neuroimaging studies, general linear modelling (GLM) was used for the first-level analyses to identify an increase or decrease of the BOLD signal in response to the treatment versus the control treatment or baseline signal (Dimoka 2012; Dulebohn et al. 2016). In most neuroscientific studies a GLM analysis is performed for each voxel ${ }^{2}$ and for each participant (Dulebohn et al. 2016). GLM analysis is appropriate when multiple predictors are used to indicate variability in a single, continuously distributed outcome variable. In this study, the outcome variable was the BOLD signal in each voxel and predictors included the rewards with their two variations (e.g. high income vs. low income). In a third step, second-level analyses were conducted to make inferences about the whole group of participants tested. Fourth, region of interest (ROI) analysis focused on the brain activity located in previously defined brain areas. The ROI analysis helped to identify whether activations in certain brain structures of the reward circuitry are linked to the strength of a person's needs. More technical information on the MRI data analysis (e.g. preprocessing steps; regressors of GLM) is provided in the "Appendix".

All analyses regarding brain activations were corrected for multiple comparisons. Whole brain activations were family-wise-error (FWE) corrected using a voxellevel FWE of $p<.05$ as a measure of significance; only activation clusters exceeding a spatial extent threshold of 49 voxels are presented (thus the activated brain area had to have a certain volume). Additionally, mean per cent signal change was extracted for each ROI using MarsBaR software (Brett et al. 2002). Per cent signal change (describing the relative change of the BOLD signal to an individual baseline) was correlated with behavioural measures of needs to study if needcongruent rewards led to more activations than need-incongruent rewards. According to Kätsyri et al. (2012), three anatomical ROIs were defined: NAcc, caudate nucleus and putamen. ROIs were defined using the Wake Forest University PickAtlas toolbox (Maldjian et al. 2003).

\footnotetext{
${ }^{2}$ A voxel is a three-dimensional cube of brain tissue that commonly contains millions of neurons and tens of billions of synapses. The number of neurons and synapses in a voxel depends on the voxel size and the area of the brain that is imaged (Huettel et al. 2009).
} 


\section{Results}

Results from this study are organized as follows: First, behavioural results regarding the performance scores and reaction times from the distraction task are presented. Behavioural results help to identify whether the participants differ regarding their number of correctly solved tasks, their reaction time, and whether the number of correctly solved tasks and reaction time varies across the three rewards. Second, to answer our hypotheses the results of the neuroscientific analyses are reported (i.e. a whole brain analysis, a conjunction analysis and a region of interest analysis).

- With respect to $\mathrm{H} 1$, we followed the standard procedure of analysing imaging data and reported results of the whole brain analysis to find out which brain areas are involved in processing high income, respectful leadership and prestigious company cars. Afterwards we conducted a conjunction analysis in order to study modality-independent and modality-dependent activations of these rewards.

- Regarding $\mathrm{H} 2$, a region of interest analysis focuses on specific reward-related brain areas and offers an answer to the question of whether rewards that closely match an employee's needs result in stronger neural activations of the reward circuitry than rewards that match these needs to a lesser extent.

\subsection{Behavioural results}

In order to test whether the participants differed regarding their number of correctly solved tasks and whether this number of correctly solved tasks varies across the three rewards, a repeated-measures ANOVA with rewards (Leader, Car, Money, and Arrow as control) and scores (Correct vs. Incorrect) was conducted. As intended by the study design, the ANOVA showed a significant main effect for the scores, indicating that more tasks were solved correctly $[F(1,43)=69.99, p<.01$, $\eta_{\mathrm{p}}^{2}=.62 ; M_{\text {Correct }}=28.85, S D_{\text {Correct }}=3.26$ vs. $M_{\text {Incorrect }}=20.93, S D_{\text {Incorrect }}=$ 3.15]. There was neither a main effect for rewards nor a significant interaction between the reward treatments/control treatment and the scores. Thus, the participants performed equally well across the different reward treatments and the control treatment.

For the reaction time (RT), again a repeated-measures ANOVA with reward (Leader, Car, Money, and Arrow as control) and scores (Correct vs. Incorrect) was performed. In this case, the ANOVA showed a main effect for scores $\left(F(1,43)=23.05, p<.01, \eta_{\mathrm{p}}^{2}=.35\right)$. In sum, correct answers were given more quickly than incorrect ones $\left(M_{\text {Correct }}=572.86, S D_{\text {Correct }}=171.86\right.$ vs. $M_{\text {Incorrect }}=$ 633.76, $\left.S D_{\text {Incorrect }}=183.27\right)$. Neither a significant main effect for rewards nor a significant interaction between the rewards/control treatment and the scores was found. Thus, study participants responded equally fast across the different rewards and the control treatment. 


\subsection{Neurophysiological results}

H1 The rewards high income, respectful leadership, and prestigious company cars share a common neural basis in the striatum and further show reward modalitydependent activation patterns.

In order to identify reward modality-dependent activation patterns for processing the three rewards of this study we first analysed the simple T-contrasts of each reward treatment as well as the control treatment (see Method section). Table 2 summarizes significant activation clusters that were found to be activated after multiple comparison correction for the 'Leader $+>$ Leader-' contrast of the leader treatment, the 'Money $+>$ Money-' contrast of the money treatment, and the 'Car $+>$ Car-' contrast of the car treatment. Results depicted in Table 2 show that when potential employees anticipate working for a respectful leader, receiving high income or driving a prestigious company car, then mainly subcortical and cortical nodes of their reward circuit are elevated. As expected, the opposing contrasts 'Leader $->$ Leader+', 'Money $->$ Money+' and 'Car- $>$ Car+'- did not result in significant activations. Therefore, when employees anticipate working for a nonrespectful leader, receiving low income, and driving a less prestigious company car then no significant neural activation clusters were observed. Table 2 further summarizes the activation clusters for the control treatment (see the "Arrow $+>\mathrm{Ar}$ row-' contrast in Table 2). Again, the 'Arrow $->$ Arrow +' contrast did not result in any significant activations.

As mentioned in the Method section, the Leader+, Money+ and Car+ treatment were always presented in the MR-scanner when participants solved a distraction task correctly. Thus, the simple T-contrasts shown in Table 2 represent both activations that occur from processing a particular reward and activations that occur from pleasure when solving a task correctly. In order to check whether there is neural activation that can be exclusively traced back to the rewards, the neural activations from the control treatment-which represented only activations related to the pleasure of solving a task correctly-was subtracted from the neural activations in each reward treatment.

Consequently, the simple T-contrasts of each reward treatment displayed in Table 2 were contrasted to the simple T-contrasts of the control treatment (see for example Stanley 2016). This should result in activation patterns that are specific to the particular rewards but that do not include activations related to the pleasure of solving a task correctly. In that vein the following contrasts were examined: ('Leader $+>$ Leader-' $>$ 'Arrow $+>$ Arrow-'), ('Money $+>$ Money-' $>$ 'Arrow $+>$ Arrow-'), and ('Car $+>$ Car-' $>$ 'Arrow $+>$ Arrow-'). Table 3 and Fig. 2 depict the activations that occurred when study participants anticipated (a) working for a respectful leader, (b) receiving a high income, and (c) driving a prestigious company car, while controlling for the confounder (i.e. the pleasure when solving a task correctly).

With respect to the respectful leader reward, analysing the contrast of the simple T-contrasts (i.e. 'Leader $+>$ Leader-' $>$ 'Arrow $+>$ Arrow-') resulted in activations within the putamen, thalamus and supplementary motor area, with these 


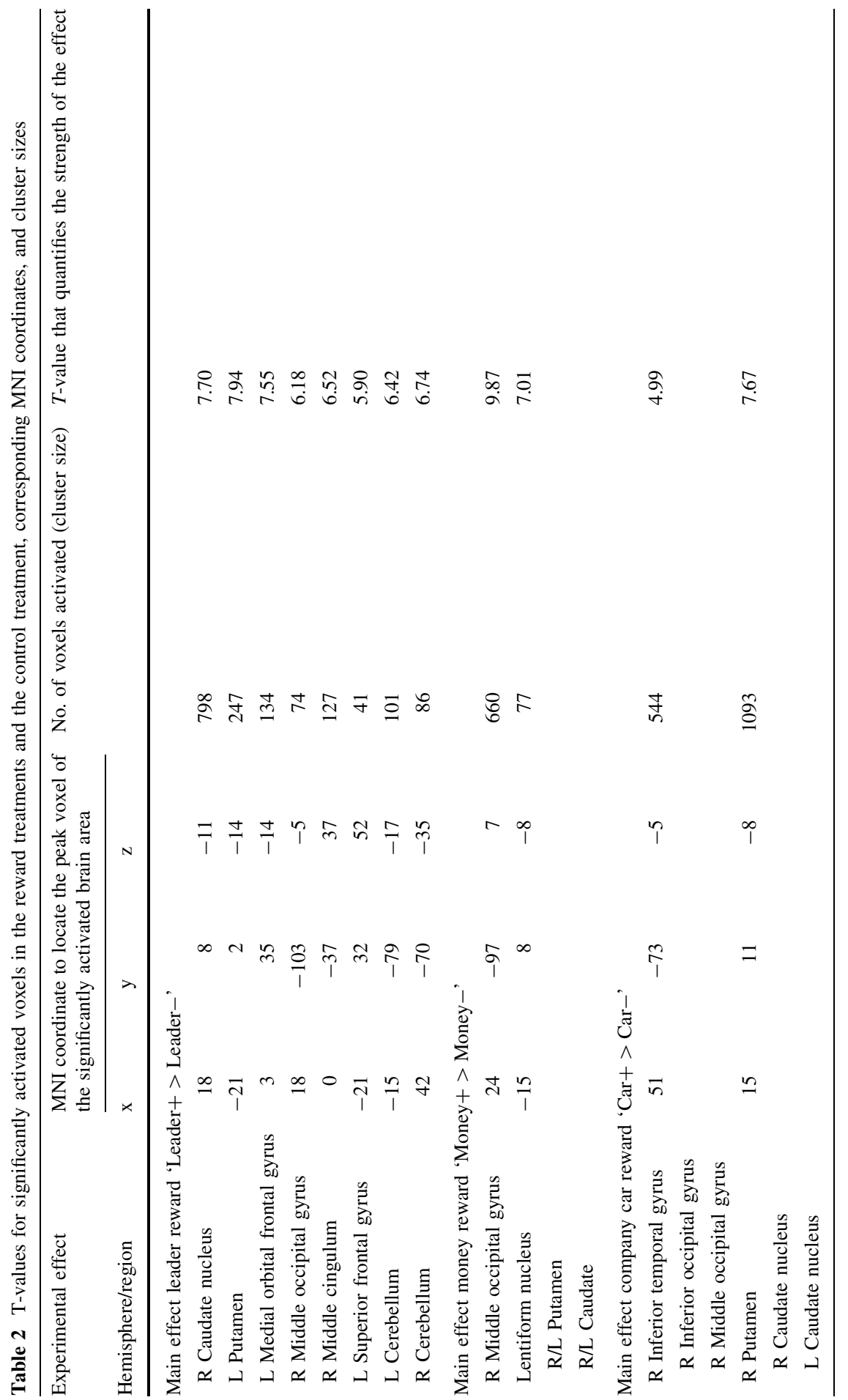




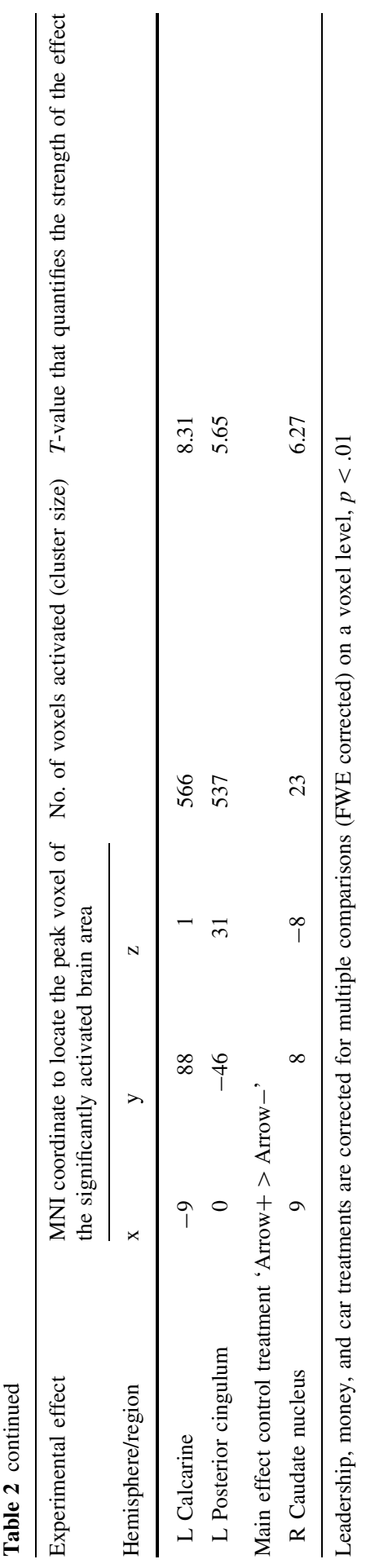




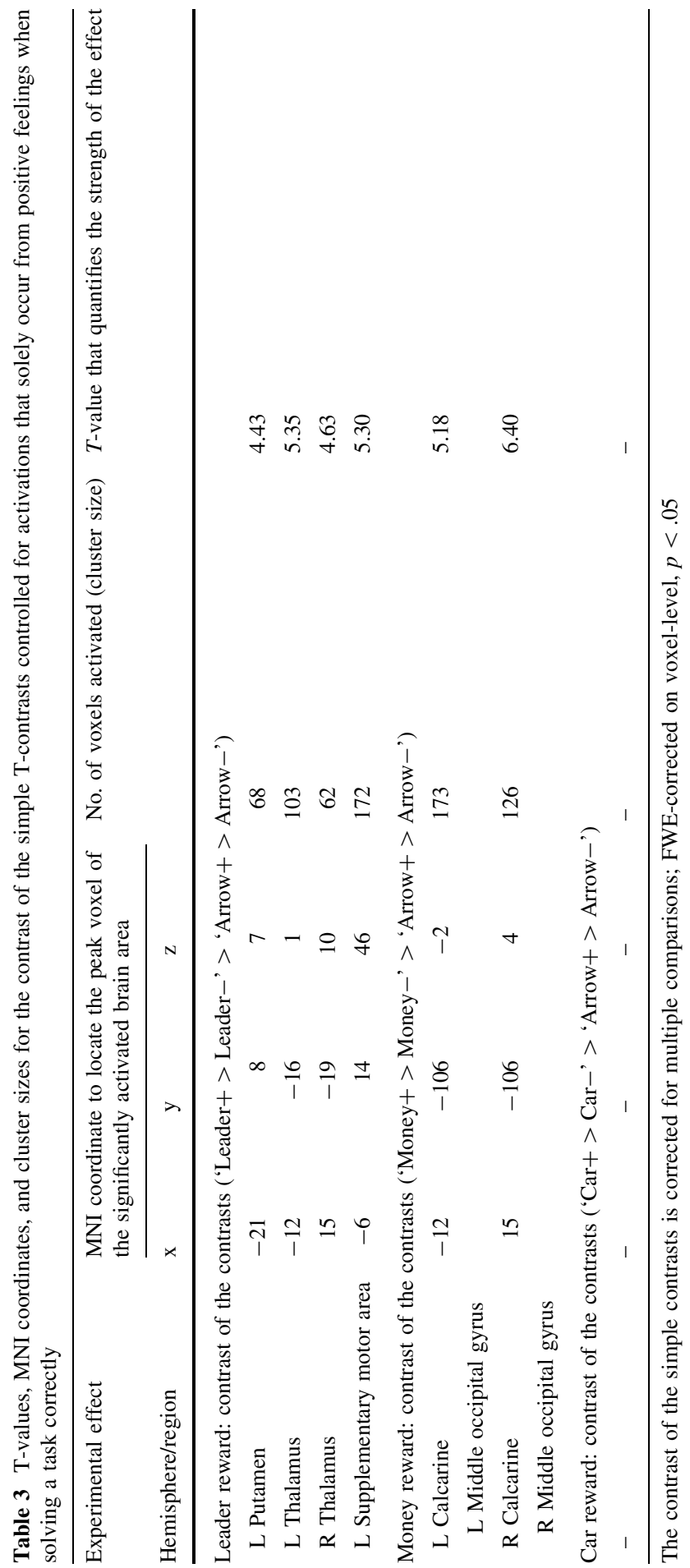




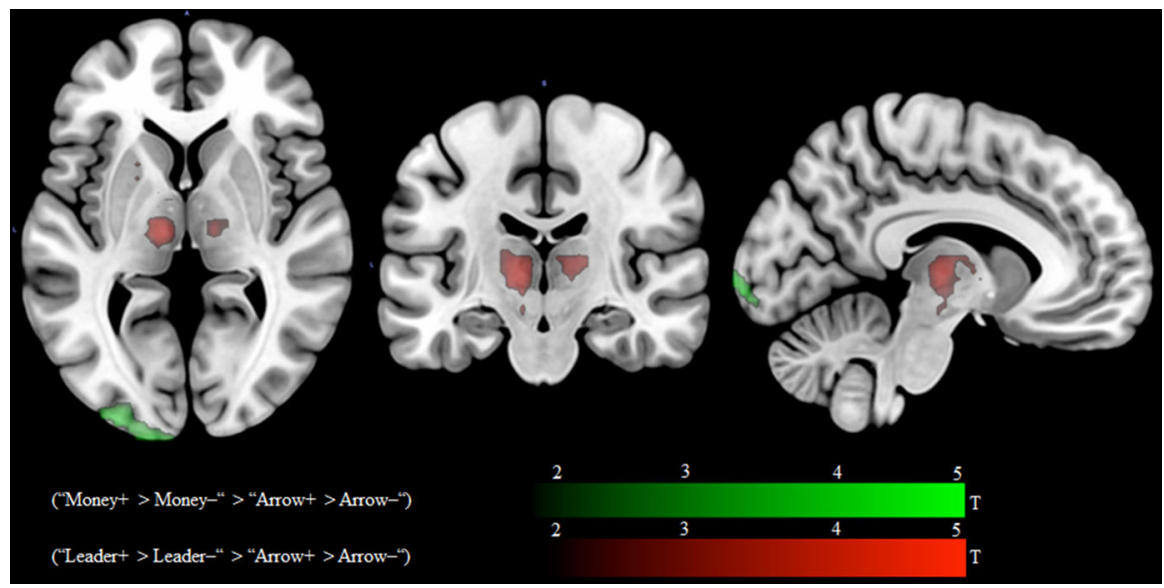

Fig. 2 Significant activation clusters for the contrast of the simple T-contrasts (corrected for multiple comparisons). FWE-corrected on voxel-level, $p<.05$ (colour figure online)

areas being more active when participants imagined working for a respectful leader as a reward (see Fig. 2 red areas). In a similar vein, when studying the financial reward, the 'Money $+>$ Money-' $>$ 'Arrow $+>$ Arrow-' contrast resulted in activations within the left and right calcarine, subsuming the middle occipital gyrus (see Fig. 2 green area). Finally, when studying the company car reward, the 'Car $+>$ Car-' $>$ 'Arrow $+>$ Arrow - ' contrast did not lead to significant activation clusters.

With respect to hypothesis 1, Table 3 and Fig. 2 show that a respectful leader, high income and a prestigious company car are perceived as rewards, even after controlling for the pleasure of solving a task correctly. Moreover, these management-related rewards activate subcortical and cortical nodes of the reward circuitry (e.g. putamen) that are also activated by more basic rewards such as foods or erotic pictures.

In order to find out whether different management-related rewards also commonly share a common neural basis, a conjunction analysis was performed. The basic idea behind this analysis is to determine whether two or more experimental treatments activate the same regions of the brain. In the current study the conjunction analysis enabled us to identify those brain areas that were commonly activated across all three reward treatments.

The conjunction was analysed using the software SPM (minimum T-statistic; Friston et al. 2005), in which the conjunction null hypothesis test was used (Nichols et al. 2005). This test requires significant regions in all tested treatments (i.e. a logical 'AND' conjunction). For the analysis, the 'Leader $+>$ Leader-', 'Car $+>$ Car-', and 'Money+ $>$ Money-' contrasts were submitted to the conjunction (corrected for multiple comparisons; FWE-corrected at $p<.05$, voxel-extent threshold $k>49$ ).

Results showed that all three rewards evoked activations in the calcarine, the lentiform nucleus subsuming the putamen, and the caudate nucleus (see Table 4 and 


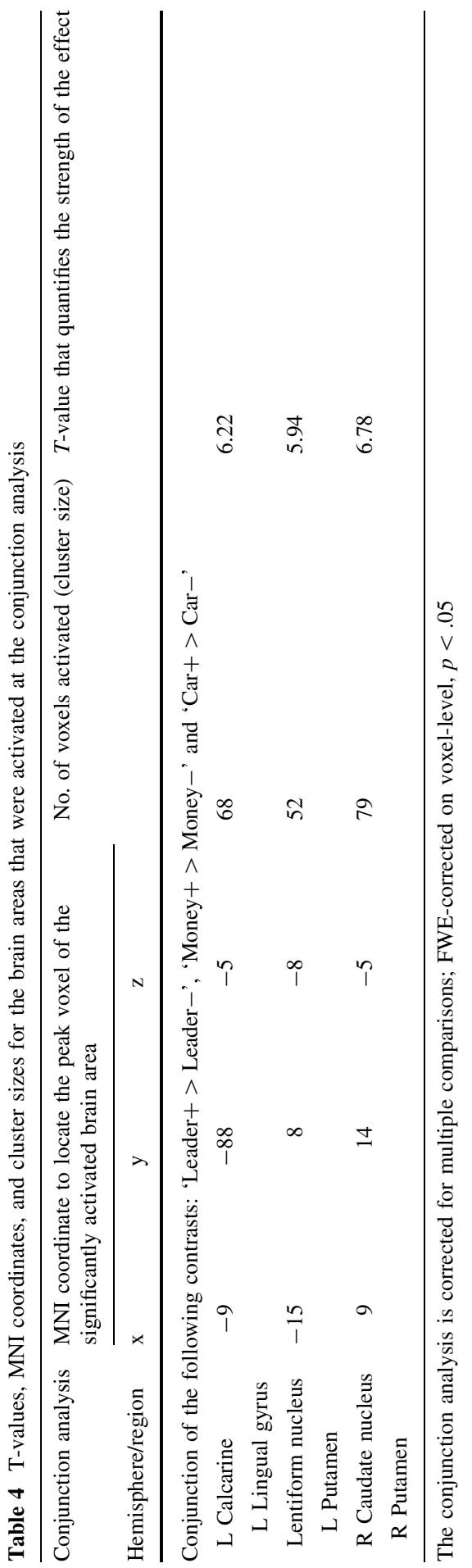




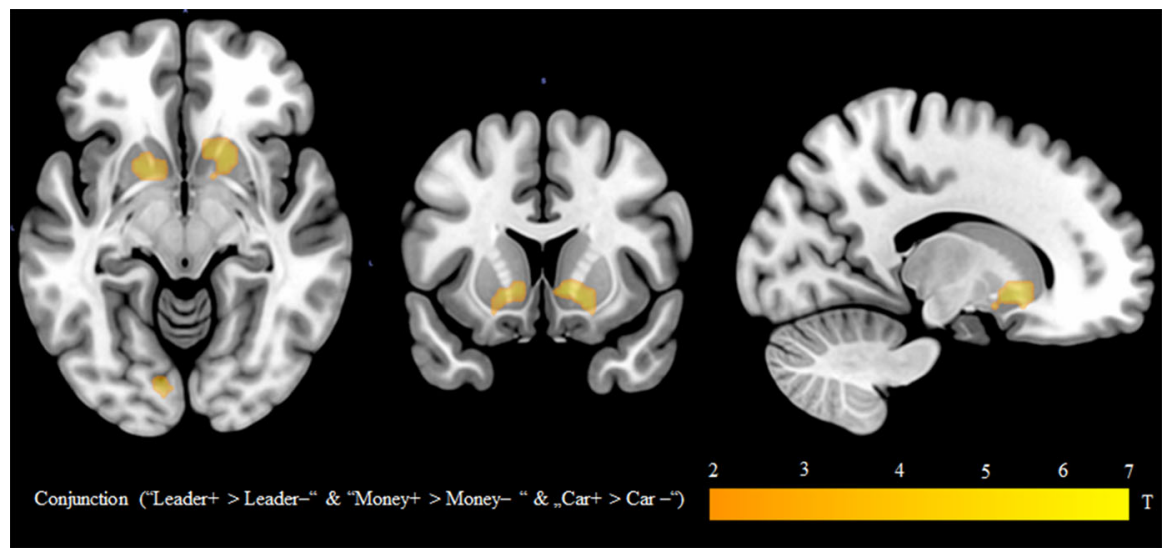

Fig. 3 Brain areas that are activated by all three rewards

Fig. 3). The findings provide some evidence for a common neural system involved in anticipating management-related rewards, involving the calcarine and the bilateral putamen.

Consequently, when findings from the conjunction analysis (Table 4 and Fig. 3) and the contrast analysis (Table 3 and Fig. 2) are considered jointly, it can be seen that on the one hand the rewards respectful leader, high income, and prestigious company car activate similar, thus modality-independent brain areas. However, on the other hand, each of these rewards also activates distinct, modality-dependent brain areas (e.g. supplementary motor area for the reward respectful leadership). Consequently, $\mathrm{H} 1$ is supported.

H2 Rewards that closely match an employee's need result in stronger neural activations of the reward circuitry than rewards that match this need to a lesser extent.

With respect to $\mathrm{H} 2$, we studied whether rewards that closely match an employee's need result in stronger neural activations of the reward circuitry than rewards that match this need to a lesser extent. Therefore, the need levels of each participant were correlated with their brain activations that occurred when this participant anticipated the corresponding rewards.

As described in the Method section, each reward was assigned to one of McClelland's (1991) needs, whereby the respectful leader represented an affiliationoriented reward, the high income represented an achievement-oriented reward and the company car represented a power-related reward. The participants' need levels were measured using the PV questionnaire (McClelland 1991). Consequently, each participant was characterized by three continuous scores representing the person's need for affiliation, achievement and power. These three continuous need levels were correlated with the per cent signal change values that were extracted for the regions of interest (see Method section).

Figure 4 summarizes all correlational results. Figure 4 a depicts that the higher the study participants' need for affiliation the stronger their activations in the NAcc 

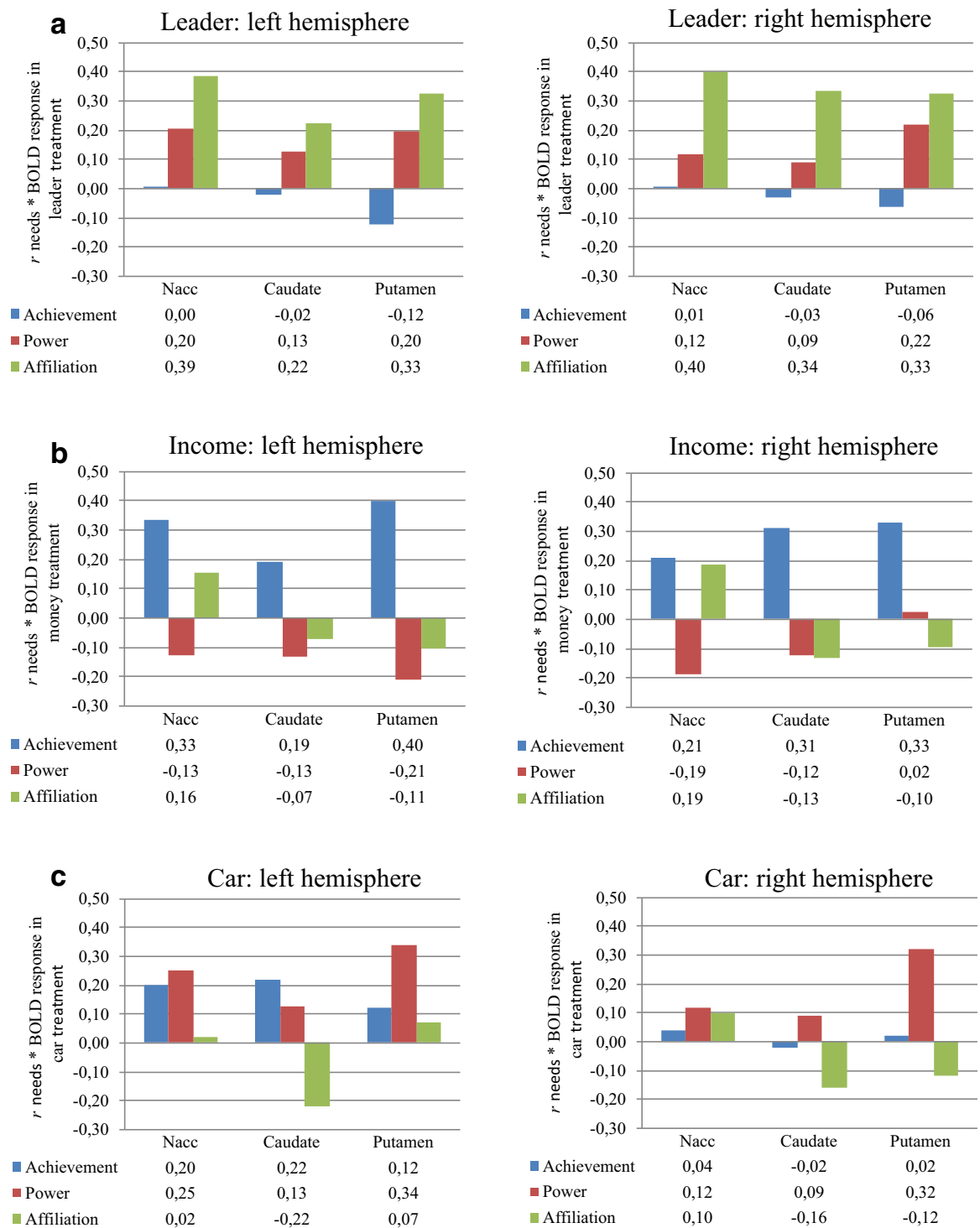

Fig. 4 Bivariate correlations between individual need level and the per cent signal change values of the ROIs NAcc, caudate and putamen for $\mathbf{a}$ the respectful leader treatment, $\mathbf{b}$ the income treatment, and $\mathbf{c}$ the company car treatment

(left/right), caudate nucleus (right) and putamen (left/right) when they anticipated working for a respectful leader $\left(r_{\mathrm{NAcc} \_1}=.39, p<.01 ; r_{\mathrm{NAcc} \_\mathrm{r}}=.40, p<.01\right.$; $\left.r_{\text {Caud_r }}=.34, p<.01 ; r_{\text {Put_1 }}=.33, p<.05 ; r_{\text {Put_r }}=.33, p<.05\right)$. In contrast to these results, the participants' need for achievement and power was not significantly related to the neural activations that occurred when they anticipated working for a respectful leader. 
Similar results were found for the high income. As can be seen in Fig. 4b participants' need for achievement was positively linked to their neural activations in the NAcc (left), caudate nucleus (right), and putamen (left/right) that occurred when the participants anticipated receiving high income $\left(r_{\mathrm{NAcc} \_1}=.33, p<.05\right.$; $\left.r_{\text {Caud_r }}=.31, p<.05 ; r_{\text {Put_1 }}=.40, p<.01 ; r_{\text {Put_r }}=.33, p<.05\right)$. Importantly, none of the remaining need levels was significantly related to the per cent signal change values.

Finally, Fig. 4c shows that the higher the persons' need for power the stronger their activations in the nucleus accumbens (left) and the putamen (left/right) when they anticipated driving a prestigious company car $\left(r_{\mathrm{NAcc} \_1}=.25, p<.05\right.$; $\left.r_{\text {Put_1 }}=.34, p<.01 ; \quad r_{\text {Put_r }}=.32, p<.05\right)$. The need for achievement and affiliation were not significantly linked to the neural activations of the car treatment.

With respect to hypothesis 2 , results from Fig. 4 show that the better a particular reward matches a person's need level the higher will be the activations in rewardsensitive ROIs (i.e. the NAcc, caudate and putamen). This finding holds true for all investigated rewards and needs: if a person had a high need for affiliation, the neural activations were stronger when the affiliation-oriented reward was offered. If a person had a high need for achievement, the neural activations were stronger when the achievement-oriented reward was offered. If a person had a high need for power, the neural activations were stronger when the power-oriented reward was offered. Consequently, $\mathrm{H} 2$ is supported by the current findings.

\section{Discussion and conclusion}

The findings of this study help to validate McClelland's (1957) need theory on a neuroscientific level. In fact, current results validate theoretical assumptions upon which that theory is built. First, it is shown if and how far different management rewards are perceived as rewarding and may contribute to work motivation. Second, based on these results we show that rewards that closely match a person's needs are perceived as more rewarding than rewards that match those needs to a lesser extent. This finding neurally validates McClelland's key assumption of a personality-based approach to work motivation. In addition, our findings extend neuroscientific literature by investigating management-relevant rewards that have not been studied before (i.e. respectful leadership, company car). In that regard, we observe that high income, respectful leadership, and a prestigious company car activate important parts of the brain's reward circuitry and are thus perceived as rewarding. In line with previous research (e.g. Sescousse et al. 2013b) these rewards trigger reward modality-dependent as well as modality-independent brain areas.

\subsection{Management-related rewards and their neurophysiological activation patterns}

In line with hypothesis 1 it is concluded that the rewards high income, respectful leadership, and prestigious company car share a common reward modalityindependent neural basis but also trigger reward modality-dependent activations. 
With respect to reward modality-independent activations we demonstrated that they lead to increased activations in the calcarine and in two areas that are commonly part of the reward circuitry-the lentiform nucleus with the putamen and the caudate nucleus. This holds particularly true for the rewards high income and respectful leadership, as the neural activations remain even after controlling for activations that result from the pleasure of solving a task correctly. This finding of reward modality-independent activations suggests that different rewards impact the same brain areas in a similar way. Therefore, it appears as if the rewards high income, respectful leadership, and prestigious company car are to some extent interchangeable on the neural level despite the circumstance that they trigger different needs of McClelland's (1957) theory.

Our findings are mostly concordant with studies investigating the overlap between social and monetary rewards. For example, Izuma et al. (2008) reported that individuals activated the putamen and caudate when they received monetary rewards. Additionally, the authors reported that the very same brain areas were activated when individuals were offered the opportunity to achieve a good reputation, whereby gaining a good reputation was seen as a non-monetary reward. Lin et al. (2012) further showed that the putamen and the caudate are both activated when individuals process a smiling face and financial benefits. In a similar vein Sescousse et al. (2013a) showed that the promise of monetary rewards elicits neural activations in the very same brain areas (i.e. the ventral striatum including the putamen and the caudate nucleus) as erotic pictures, whereby the latter represented non-monetary rewards. Taken together, findings from previous studies and results from the current study provide evidence for the idea that the neural representations for financial rewards and non-financial rewards partly overlap and are, on a neural level, to some extent interchangeable.

Reward modality-dependent brain activations were found in particular for the superior frontal gyrus or the inferior temporal gyrus, which was only activated when either the reward respectful leadership or high income was used. The prospect of high income evoked neural activations in the middle occipital gyrus after controlling for activations that resulted from the pleasure of answering correctly. In light of previous findings our results indicate that anticipating higher income activates brain regions that are typically linked to positive arousal, processing (pleasant) visual stimuli, reward, and value of probabilistic rewards. Neuroimaging findings, for instance, have revealed that watching pleasant pictures and words leads to greater activation in the middle occipital gyrus than watching neutral ones (MourãoMiranda et al. 2003; Rotshtein et al. 2001). In addition, the middle occipital gyrus is activated when emotions associated with autobiographical memories are regulated (Kross et al. 2009) or when rewards of high value are expected (e.g. Marsh et al. 2007).

Regarding the reward respectful leadership, the participants' putamen, thalamus and the supplementary motor area were activated after controlling for the pleasure of answering correctly. Based on earlier findings our study suggests that a respectful leadership style activates core components of the reward-related neurocircuitry. According to Liu et al. (2011), the activated brain areas are common parts of the neural network underlying reward processing. Kohls et al. (2013), for instance, 
found activations in the putamen and thalamus when social approval was anticipated, whereas Smith et al. (2010) reported activations in these two brain areas when research participants felt rewarded after looking at attractive faces. Parallel to our findings, Hu et al. (2015) recently showed that activations in both the putamen and the thalamus occurred when individuals were rewarded by a smile from another person. Additionally, Pfeiffer et al. (2014) reported that putamen and thalamus activations were found when participants interacted with another person in an experiment, while these activations were not found when participants interacted with a computer.

With respect to the third reward of this study, results show that the prestigious company car elevates the inferior temporal gyrus, the putamen plus the caudate nucleus, the calcarine and the posterior cingulum. After adjusting the participants' brain activations for activations that occurred from solving a task correctly, the wholebrain analysis did not result in significant activation clusters. Therefore, the findings need to be interpreted with caution. However, the unadjusted results indicate that the chance of driving a prestigious company car primarily evokes activations in the inferior temporal gyrus. Previous research suggests that this area is associated with aesthetics, rewards and personal involvement. Schaefer et al. (2015) demonstrated, for example, that the inferior temporal gyrus was more strongly activated when individuals were more deeply involved in tasks. The calcarine and posterior cingulate is often triggered when processing aesthetic art (i.e.; Lutz et al. 2013; Tsukiura and Cabeza 2011) and the putamen is associated with rewards (Kohls et al. 2013).

\subsection{Matching personal needs and rewards}

With regard to hypothesis 2 it was argued that rewards that closely match a person's needs result in stronger neural activation of the reward circuitry than rewards that match these needs to a lesser extent. Our findings are in full support of this assumption and show that when individual needs closely relate to the offered rewards these rewards are perceived as more rewarding. In detail, if a person with a high need for achievement was rewarded with high income then this person showed stronger activation of the key parts in the reward circuitry compared to receiving the reward prestigious company car or respectful leadership. A corresponding pattern occurred in persons with a high need for affiliation when they had the chance to work for a respectful leader and for persons with a high need for power when they were rewarded with a prestigious company car.

Our region of interest analysis showed that three brain areas of the reward circuitry-the nucleus accumbens, putamen and caudate nucleus-are more activated when rewards closely match a person's need level. This is particularly true for the rewards high income and respectful leadership. Based on these findings it is suggested that the nucleus accumbens, putamen and caudate nucleus are sensitive to processing close matchings between needs and rewards. These results are in line with findings by Schultheiss et al. (2008), who reported that individuals with a high need for power show stronger activation in brain structures involved in motivation (e.g. the striatum) when watching need-congruent pictures. In contrast, individuals with weak power needs did not display such strong neural activations. A 
similar result was found for the need for affiliation, albeit not in a management or work context. Quirin et al. (2013) found that the need for affiliation predicted activity in the putamen only when study participants watched video clips with a strong reference to the affiliation motive (i.e. love stories). Thus, activity in the putamen was sensitive to affiliation need-congruent stimuli. With respect to the need for achievement, Mizuno et al. (2008) showed that the putamen of study participants was more strongly activated when they received feedback on their task performance compared to when they received performance-contingent pay.

\subsection{Implications for motivation theory and management practice, limitations, and future research}

Our findings support a personality-based approach to work motivation and suggest considering the needs of employees when setting up effective reward systems. We provide neural support for the assumption that work motivation results from an interaction of internal factors (e.g. needs) and external factors (e.g. rewards). As this isto the best of our knowledge - the first study that investigates the neural basis of different management-related rewards and their match to McClelland's needs, our study may be used to strengthen and expand motivation theory. More particularly, we uniquely validate McClelland's (1985) theory as we were able to demonstrate the importance of the matching between McClelland's needs and congruent rewards on a neural level.

Our findings might also be used to refresh the discussion on conscious and unconscious needs or motives, as was required by Steers et al. (2004) in their statement on the future of work motivation theory. While individuals are aware of their conscious needs and are able to express them verbally (e.g. in a questionnaire), they lack access to or awareness of their unconscious needs. Consequently, unconscious needs or motives are difficult to measure and neuroscientific techniques may offer new methods to approach them in a more valid way. By using new methodological approaches the long-standing discussion on whether conscious and unconscious needs are related could gain new impulse. Additionally, our study provides findings that could be referred to when comparing the neural activations of rewards matched with conscious needs to the activations of the same rewards matched with unconscious needs.

What managerial implications can we draw from our results? From a practical point of view, our findings suggest that not only high income but also a respectful leader and a prestigious company car are perceived as rewarding. Moreover, these rewards are, on a neural level, to some extent interchangeable as they activate mutual brain areas. That is, a prestigious company car or respectful leadership may substitute a pay rise within a reward system to some extent. This finding could therefore be used to encourage certain diversity in the use of management rewards. In today's work environment money is undoubtedly the most common reward (Gunkel et al. 2009) but our results suggest that other types of rewards might be similarly effective. Therefore, we suggest extending the role of non-monetary rewards at the workplace (e.g. a good leader, a sound working atmosphere or other non-monetary benefits) because a higher income or financial bonuses might be too short-sighted in many cases. 
We also find that personality-based rewards are more rewarding, and thus are presumed to impact on motivation to a greater extent. Consequently, organizations should consider their employees' needs when setting up reward systems. According to our findings, individuals with a high need for achievement, affiliation or power are more effectively rewarded by a closely corresponding reward. Rewards that do not closely match an employee's needs may also be rewarding but, according to our results, certainly to a lesser extent. Therefore, reward systems that consider the importance of this match provide the chance of having a higher impact on the employee's motivation and, thus, might also be more efficient.

Finally, as our findings suggest that there is potential benefit for organizations in knowing the predominant needs of their employees, organizations might sensitize leaders to determine information about these individual needs. Moreover, leaders could adapt their leadership style so that employees are motivated to express their predominant needs. Either way, using individual needs for motivational purposes requires being informed about them.

In this study certain limitations should be considered. Practical restrictions forced us to hypothetically reward the study participants and therefore we only provided a fixed pay-off. We are aware of the fact that economic experiments are usually fully incentivized, while study designs commonly used in social neurosciences do not necessarily deem this. With respect to our treatments (money, respectful leader, company car) we decided to incentivize none of these treatments to avoid potential confounding effects when only a monetary compensation could have been provided. Consequently, all three rewards were presented hypothetically. However, results should not be biased except if the hypothetical rewarding differentially impacts on neural activations within the three reward treatments (e.g. Falk et al. 2008). In this regard, there is evidence that supports the validity of using hypothetical rewards in experiments (e.g. Madden et al. 2003, 2004), which is why no such differential bias was expected for the current study. Nevertheless, we acknowledge that this might limit the validity of our study and it is certainly worth also studying the neurophysiological foundation of rewards that are actually given to study participants in future studies. Secondly, we did not investigate cultural differences regarding rewards. Future research might address this issue and study the impact of cultural preferences regarding rewards and the match between need and rewards. Thirdly, the participants of our study were MBA students. Even though they had work experience it might be valuable to conduct a future study on employees, as the relevance of rewards may depend on the years of work experience. Fourthly, due to the fact that in the current study participants had to stay in the MR-scanner for approximately $45 \mathrm{~min}$, fatigue effects are possible. Thus, the length of the experiment might have influenced neurological findings. Moreover, as in most experimental studies, the question remains open as to whether the results of this study hold for real-life settings outside the laboratory (i.e. the study's external validity needs to be proven). However, studies looking into the external validity of subjects' behaviour in the laboratory usually show promising results (e.g. Benz and Meier 2008; Rustagi et al. 2010). Finally, this study was limited to investigating certain needs and rewards. Thus, the generalizability of current findings to other needs or rewards might be limited and should be made with caution. Future studies 
could, for example, include needs from other theories (e.g. Maslow 1943) and could further replicate the results with additional rewards.

Acknowledgements Open access funding provided by University of Graz. We would like to thank Karl Koschutnig, Jürgen Fleiss and Jakob Perktold for their comments on an earlier version of this manuscript. This fMRI-experiment was part of a larger study on applied neuroscience. Selected parts of this larger study are under revision in another scientific journal.

Open Access This article is distributed under the terms of the Creative Commons Attribution 4.0 International License (http://creativecommons.org/licenses/by/4.0/), which permits unrestricted use, distribution, and reproduction in any medium, provided you give appropriate credit to the original author(s) and the source, provide a link to the Creative Commons license, and indicate if changes were made.

\section{Appendix}

\section{Additional information on the human brain}

Anatomically, the brain can be structured into several areas. The important point is that these areas contribute to different tasks. Some areas are responsible for conscious perception, thinking, and acting. Others are engaged, for example, in motoric processes, repetitive automatisms, emotions or vital functions. This knowledge is not really new as we have known about key regions and their function for many years from brain injuries, in which persons have lost their ability for a specific task (e.g. a person is no longer able to speak); but with the use of contemporary methods this knowledge has been deepened and we can locate even small areas on a very detailed basis. To provide an idea of the accuracy now possible: voxels, the basic sampling units of MRI, are about one to two $\mathrm{mm}$ in each dimension in structural MRI or three to five $\mathrm{mm}$ in functional MRI (Huettel et al. 2009).

As a consequence, a verbal description of brain areas (such as the 'occipital gyrus' or 'amygdala') is no longer sufficient in scientific discussion. For a better positioning and description of activated brain areas, further classifications are now used. In publications, the fragmentation of the brain into 52 areas by Brodman, the 3D coordinate-system by Talaraich, or the MNI templates developed by the Montreal Neurological Institute are often cited (Ahlert and Kenning 2006; Poldrack et al. 2011). These and other classifications and coordinates allow us to clearly and distinctly allocate specific parts in the brain.

Similarly, our knowledge about tasks and functions of different brain regions has expanded dramatically. We can differentiate parts in our brain that-broadly speaking - contribute to, for example, emotions, listening, calculating, social cognition, decision-making, speaking and so forth. In the meantime the literature on brain areas, associated networks and their function has become increasingly fragmented, containing numerous results, partial results, and contradictory findings. For this reason it is absolutely indispensable to elaborate the relevant literature at length before jumping to conclusions. 


\section{Additional information on neuroscientific instruments}

In neuroscientific research, various methods are used that differ in technical functionality and especially in spatial and temporal resolution. ${ }^{3}$ Electroencephalography (EEG) and the magnetoencephalography (MEG) measure electrical currents or magnetic fields that occur in the brain. Positron emission tomography (PET) and (functional) magnetic resonance imaging (fMRI) capture metabolic changes in the brain. During PET, radioactive substances are injected, which can be recorded throughout the examination. During fMRI, the different magnetic characteristics of deoxygenated and oxygenated blood are captured.

Of those methods, EEG and MEG have the highest temporal resolution due to the possible measurement of activation changes in only milliseconds. Spatial resolution is the most exact in fMRI and enables the localization of activation down to a few millimetres. fMRI, PET and MEG are able to depict subcortical areas, whereas EEG basically cannot depict subcortical structures. In addition, numerous other methods exist in neurosciences (e.g. intracranial electroencephalography (iEEG), genetic studies, pharmacological interventions, transcranial magnetic stimulation (TMS), electrical stimulations, and examination of brain damage), which would not be appropriate for the use in neuroeconomics because they are unsuitable in terms of spatial and temporal resolution or their application for non-medical purposes is restricted due to ethical reasons.

In recent years, (f)MRI has become the most popular method used in neuroeconomic research. As already mentioned, there are two possible ways to use an MRI-scanner, either for a structural or for a functional scan of the human brain. The first depicts the brain and its structures (e.g. lobes) and is used to examine the anatomy of the human brain. The latter-fMRI-enables the observation of brain activity. It pictures the functioning human brain in a proper spatial and temporal resolution of a few millimetres and seconds (Huettel et al. 2009). Its good resolution is the reason why this method can be used in social science. Spatial results are accurate and the delay between task-solving and imaging is sufficiently small to allow the testing of scientific hypotheses.

Even when the technical details are complicated, neuroscientists use a somehow simple idea to measure brain activity. As we already know, during the solving of a task some brain areas are activated and others are not. These activated areas require energy and therefore they consume oxygen, which is transported by the blood (Huettel et al. 2009). Oxygenated blood has magnetic characteristics other than those of deoxygenated blood and these differences can be measured with a strong magnet-an MRI-scanner. This contrast is called the BOLD signal (bloodoxygenation-level-dependent contrast). When a brain area is activated, oxygen is consumed, which results in a change of the BOLD contrast. This allows conclusions to be made on whether a brain area contributes to solving a specific task or not. For the sake of accuracy we want to point out that we do not measure neural activity directly but rather the metabolic consequence of this activation (Huettel et al. 2009).

\footnotetext{
3 A short description of the most important methods can be found in various articles (e.g., Camerer et al. 2005; Ahlert and Kenning 2006; Peters and Ghadiri 2011; Reimann and Weber 2011). For a more indepth discussion of the subject of fMRI see Huettel et al. (2009) or Poldrack et al. (2011).
} 


\section{Additional information on MRI data acquisition}

In this study all stimuli were presented using Presentation 16.0 (Neurobehavioral Systems, Albany, CA, USA) and projected onto a semi-translucent screen positioned approximately $1.5 \mathrm{~m}$ in front of the scanner. All participants wore a head coil with an attached mirror to allow them to view the visual stimuli on the vertically mounted screen.

Imaging was done on a 3.0T Magnetom Skyra (Siemens Medical Systems, Erlangen, Germany) using a 32-channel head coil. For each treatment, 276 BOLDsensitive $\mathrm{T} 2 *$-weighted functional images were acquired using a single-shot gradientecho EPI pulse sequence $\left(\mathrm{TR}=2400 \mathrm{~ms}, \mathrm{TE}=30 \mathrm{~ms}\right.$, flip angle $=90^{\circ}$, slice thickness $=3.5 \mathrm{~mm}$, distance factor $=0 \%$, base resolution $68 \times 68$, $\mathrm{FOV}=240 \mathrm{~mm}, 36$ slices per volume). Images were recorded transversally in interleaved ascending mode and parallel to the anterior commissure-posterior commissure (AC-PC) plane. Additionally, high-resolution structural images were acquired using a T1-weighted MPRAGE sequence $(\mathrm{TR}=2530 \mathrm{~ms}, \mathrm{TE}=2.26 \mathrm{~ms}$, flip angle $=9^{\circ}$, matrix $256 \times 256, \mathrm{FOV}=256 \mathrm{~mm}$, voxel size $=1 \mathrm{~mm}^{3}$ isotropic)

\section{Additional information on MRI data analysis}

Functional MRI data analysis was performed using Statistical Parametric Mapping 8 (SPM8; Wellcome Dept. of Imaging Neuroscience, London, UK). Preprocessing steps included motion correction (all functional images were spatially realigned to the first functional image), slice time acquisition correction, and spatial normalization into the standard space (Montreal Neurological Institute; MNI) using the Echo-Planar Imaging (EPI) template provided in SPM8. Finally, the functional data were smoothed using a Gaussian filter of $8 \mathrm{~mm}$. A high-pass filter with a cut-off frequency of $1 / 128 \mathrm{~Hz}$ was employed in order to remove low-frequency drifts.

At the first level of the analysis, each participant's preprocessed data were analysed using the principles of the general linear model (GLM), as implemented in SPM8, on a voxel-by-voxel basis. Thus, we modelled regressors within each trial (Correct vs. Incorrect, as indicated by the green framing when the feedback was given; please see Fig. 1). Additionally, we modelled three regressors of no-interest (Mask, Fixation and Motor Response, which indicated individual reaction time). Linear t-contrasts (Correct $>$ Incorrect and Incorrect $>$ Correct) were computed.

At the second level, the contrast images from all participants were entered into a one-sample t-test to assess the population mean effects. At this point it is important to note that the symbol for high income (i.e. a bundle of banknotes; Money+) was always framed when the task was solved correctly, whereas the symbol for low income (i.e. a few coins; Money-) was always framed when the task was solved incorrectly. Thus, the simple contrast in the money treatment can be described as

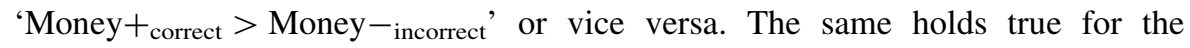
remaining treatments and the control treatment. Since the simple contrasts of the treatments are confounded with correct/incorrect answers, a contrast of the simple contrasts was calculated in order to identify brain regions sensitive to the rewards but controlling for activations that evoke from the pleasure of answering a task 
correctly (see e.g. Gureckis et al. 2011). Thus, the following contrast of simple contrasts was calculated: 'Money $+_{\text {correct }}>$ Money $-{ }_{\text {incorrect }}>\left(\right.$ Arrow $+{ }_{\text {correct }}>$ Arrow- ${ }_{\text {incorrect }}$ ). Since the simple contrast of money treatment and the control represents neural activations that relate to the pleasure of solving a task correctly, these reward-associated activations remain unnoted in the contrast of the simple contrasts.

Whole brain activations were family-wise-error (FWE) corrected for multiple comparisons using a voxel-level FWE of $p<.05$, as a measure of significance; only activation clusters exceeding a spatial extent threshold of 49 voxels are presented. Additionally, mean per cent signal change was extracted for each ROI using MarsBaR software (Brett et al. 2002). Per cent signal change was related to individual ratings on needs.

\section{References}

Ahlert D, Kenning PH (2006) Neuroökonomik (Neuroeconomics). Z Manag 1(1):22-45. doi:10.1007/ s12354-006-0003-8

Ashby FG (2011) Statistical analysis of fMRI data. MIT Press, Cambridge

Bandura A (1977) Social learning theory. Cliffs, Englewood

Bass BM, Avolio BJ (1995) MLQ Multifactor Leadership Questionnaire: technical report. Mind Garden, Redwood City

Baumann N, Kaschel R, Kuhl J (2005) Striving for unwanted goals: stress-dependent discrepancies between explicit and implicit achievement motives reduce subjective well-being and increase psychosomatic symptoms. J Pers Soc Psychol 89(5):781-799. doi:10.1037/0022-3514.89.5.781

Becker TE, Kernan MC, Clark KD, Klein HJ (2015) Dual commitments to organizations and professions: different motivational pathways to productivity. J Manag. doi:10.1177/0149206315602532

Beckmann J, Heckhausen H (2008) Motivation as a function of expectancy and incentive. In: Heckhausen J, Heckhausen H (eds) Motivation and action. Cambridge University Press, New York, pp 99-136

Benz M, Meier S (2008) Do people behave in experiments as in the field? Evidence from donations. Exp Econ 11(3):268-281. doi:10.1007/s10683-007-9192-y

Bilsky W, Schwartz SH (2008) Measuring motivations: integrating content and method. Pers Individ Differ 44(8):1738-1751. doi:10.1016/j.paid.2008.02.001

Boezeman EJ, Ellemers N (2007) Volunteering for charity: pride, respect, and the commitment of volunteers. J Appl Psychol 92(3):771-785. doi:10.1037/0021-9010.92.3.771

Boezeman EJ, Ellemers N (2014) Volunteer leadership: the role of pride and respect in organizational identification and leadership satisfaction. Leadership 10(2):160-173. doi:10.1177/ 1742715012467487

Boyce CJ, Wood AM (2011) Personality and the marginal utility of income: personality interacts with increases in household income to determine life satisfaction. J Econ Behav Org 78(1-2):183-191. doi:10.1016/j.jebo.2011.01.004

Braun S, Peus C, Weisweiler S, Frey D (2013) Transformational leadership, job satisfaction, and team performance: a multilevel mediation model of trust. Leadersh Q 24(1):270-283. doi:10.1016/j. leaqua.2012.11.006

Braus DF, Wrase J, Grusser S, Hermann D, Ruf M, Flor H, Mann K, Heinz A (2001) Alcohol-associated stimuli activate the ventral striatum in abstinent alcoholics. J Neural Transm (Vienna) 108(7):887-894. doi:10.1007/s007020170038

Brett M, Anton J-L, Valabregue R, Poline J-B (2002) Region of interest analysis using an SPM toolbox. Presented at the 8th international conference on functional mapping of human brain, Sendai, Japan

Brunstein JC, Hoyer S (2002) Implizites versus explizites Leistungsstreben: Befunde zur Unabhängigkeit zweier Motivationssysteme. Z Padagog Psychol 16(1):51-62. doi:10.1024//1010-0652.16.1.51 
Brunstein JC, Schultheiss OC, Grässman R (1998) Personal goals and emotional well-being: the moderating role of motive dispositions. J Pers Soc Psychol 75(2):494-508. doi:10.1037//0022-3514. 75.2 .494

Byron K, Khazanchi S (2012) Rewards and creative performance: a meta-analytic test of theoretically derived hypotheses. Psychol Bull 138(4):809-830. doi:10.1037/a0027652

Cacioppo JT, Tassinary LG, Berntson G (2007) Handbook of psychophysiology. Cambridge University Press, Cambridge

Camerer CF, Loewenstein G, Prelec D (2005) Neuroeconomics: how neuroscience can inform economics. J Econ Lit 43(1):9-64

Campbell DJ, Pritchard RD (1976) Motivation theory in industrial and organizational psychology. In: Dunnette MD (ed) Handbook of industrial and organizational psychology. Rand McNally College Pub. Co, Chicago, pp 63-130

Cerasoli CP, Nicklin JM, Ford MT (2014) Intrinsic motivation and extrinsic incentives jointly predict performance: a 40-year meta-analysis. Psychol Bull 140(4):980-1008. doi:10.1037/a0035661

Condly SJ, Clark RE, Stolovitch HD (2003) The effects of incentives on workplace performance: a metaanalytic review of research studies 1. Perform Improv Q 16(3):46-63. doi:10.1111/j.1937-8327. 2003.tb00287.x

Costa AJ, Silva JBL, Chagas PP, Krinzinger H, Lonneman J, Willmes K, Wood G, Haase VG (2011) A hand full of numbers: a role for offloading in arithmetics learning? Front Psychol 2:368-372. doi:10. 3389/fpsyg.2011.00368

de Gieter S, Hofmans J (2015) How reward satisfaction affects employees' turnover intentions and performance: an individual differences approach. Hum Resour Manag J 25(2):200-216. doi:10. 1111/1748-8583.12072

Deci EL, Koestner R, Ryan RM (1999) A meta-analytic review of experiments examining the effects of extrinsic rewards on intrinsic motivation. Psychol Bull 125(6):627-668. doi:10.1037/0033-2909. 125.6.627

Dehaene S, Izard V, Piazza M (2005) Control over non-numerical parameters in numerosity experiments. www.unicog.org/docs/DocumentationDotsGeneration.doc

Dimoka A (2012) How to conduct a functional magnetic resonance (fMRI) study in social science research. MIS Q 36(3):811-840

Dufner M, Arslan RC, Hagemeyer B, Schönbrodt FD, Denissen JJA (2015) Affective contingencies in the affiliative domain: physiological assessment, associations with the affiliation motive, and prediction of behavior. J Pers Soc Psychol 109(4):662-676. doi:10.1037/pspp0000025

Dulebohn JH, Davison RB, Lee SA, Conlon DE, McNamara G, Sarinopoulos IC (2016) Gender differences in justice evaluations: evidence from fMRI. J Appl Psychol 101(2):151-170. doi:10. 1037/apl0000048

Ebner NC (2008) Age of face matters: age-group differences in ratings of young and old faces. Behav Res Methods Instrum Comput 40(1):130-136. doi:10.3758/BRM.40.1.130

Eisenberger R, Jones JR, Stinglhamber F, Shanock L, Randall AT (2005) Flow experiences at work: for high need achievers alone? J Org Behav 26(7):755-775. doi:10.1002/job.337

Engeser S, Langens T (2010) Mapping explicit social motives of achievement, power, and affiliation onto the five-factor model of personality. Scand J Psychol 51(4):309-318. doi:10.1111/j.1467-9450.2009. 00773.x

Falk A, Fehr E, Fischbacher U (2008) Testing theories of fairness: intentions matter. Game Econ Behav 62(1):287-303. doi:10.1016/j.geb.2007.06.001

Fehr E, List JA (2004) The hidden costs and returns of incentives trust and trustworthiness among CEOs. J Eur Econ Assoc 2(5):743-771. doi:10.1162/1542476042782297

Felfe J, Goihl K (2002) Transformational leadership and commitment. In: Felfe J (ed) Organizational development and leadership, vol 11. Lang, Frankfurt am Main, pp 87-124

Felfe J, Schyns B (2006) Personality and the perception of transformational leadership: the impact of extraversion, neuroticism, personal need for structure, and occupational self-efficacy. J Appl Soc Psychol 36(3):708-739. doi:10.1111/j.0021-9029.2006.00026.x

Friston KJ, Penny WD, Glaser DE (2005) Conjunction revisited. Neuroimage 25(3):661-667. doi:10. 1016/j.neuroimage.2005.01.013

Griskevicius V, Tybur JM, van den Bergh B (2010) Going green to be seen: status, reputation, and conspicuous conservation. J Pers Soc Psychol 98(3):392-404. doi:10.1037/a0017346

Gunkel M, Lusk EJ, Wolff B (2009) Country-compatible incentive design. Schmalenbach Bus Rev 61:290-309 
Gureckis TM, James TW, Nosofsky RM (2011) Re-evaluating dissociations between implicit and explicit category learning: an event-related fMRI study. J Cogn Neurosci 23(7):1697-1709. doi:10.1162/ jocn.2010.21538

Haber SN, Knutson B (2010) The reward circuit: linking primate anatomy and human imaging. Neuropsychopharmacology 35(1):4-26. doi:10.1038/npp.2009.129

Hendijani R, Bischak DP, Arvai J, Dugar S (2016) Intrinsic motivation, external reward, and their effect on overall motivation and performance. Hum Perform 29(4):251-274. doi:10.1080/08959285.2016. 1157595

Hennighausen C, Hudders L, Lange BP, Fink H (2016) What if the rival drives a porsche? Evol Psychol 14(4):147470491667821. doi:10.1177/1474704916678217

Herzberg F, Mausner B, Snyderman BB (1959) The motivation to work. Wiley, New York

Hofer J, Chasiotis A (2003) Congruence of life goals and implicit motives as predictors of life satisfaction: cross-cultural implications of a study of Zambian male adolescents. Motiv Emot 27(3):251-272. doi:10.1023/A:1025011815778

Houston J, Harris P, McIntire S, Francis D (2002) Revising the Competitiveness Index using factor analysis. Psychol Rep 90(1):31-34. doi:10.2466/pr0.2002.90.1.31

Hu J, Qi S, Becker B, Luo L, Gao S, Gong Q, Hurlemann R, Kendrick KM (2015) Oxytocin selectively facilitates learning with social feedback and increases activity and functional connectivity in emotional memory and reward processing regions. Hum Brain Mapp 36(6):2132-2146. doi:10.1002/ hbm. 22760

Huettel SA, Song AW, McCarthy G (2009) Functional magnetic resonance imaging, 2nd edn. Sinauer, Sunderland

Izuma K, Saito DN, Sadato N (2008) Processing of social and monetary rewards in the human striatum. Neuron 58(2):284-294. doi:10.1016/j.neuron.2008.03.020

Jeffrey SA (2009) Justifiability and the motivational power of tangible noncash incentives. Hum Perform 22(2):143-155. doi:10.1080/08959280902743659

Jenkins GD Jr, Mitra A, Gupta N, Shaw JD (1998) Are financial incentives related to performance? A meta-analytic review of empirical research. J Appl Psychol 83(5):777-787. doi:10.1037/0021-9010. 83.5.777

Kanfer R (1991) Motivation theory and industrial and organizational psychology. In: Dunnette MD, Hough LM (eds) Handbook of industrial and organizational psychology. Consulting Psychologists Press, Palo Alto, pp 75-170

Karama S, Lecours AR, Leroux J-M, Bourgouin P, Beaudoin G, Joubert S, Beauregard M (2002) Areas of brain activation in males and females during viewing of erotic film excerpts. Hum Brain Mapp 16(1):1-13. doi:10.1002/hbm.10014

Kätsyri J, Hari R, Ravaja N, Nummenmaa L (2012) The opponent matters: elevated fMRI reward responses to winning against a human versus a computer opponent during interactive video game playing. Cereb Cortex 23(12):2829-2839. doi:10.1093/cercor/bhs259

Kellett JB, Humphrey RH, Sleeth RG (2002) Empathy and complex task performance: two routes to leadership. Leadersh Q 13(5):523-544. doi:10.1016/S1048-9843(02)00142-X

Kern ML, Friedman HS (2008) Do conscientious individuals live longer? A quantitative review. Health Psychol 27(5):505-512. doi:10.1037/0278-6133.27.5.505

Kirkcaldy B, Furnham A (1993) Predictors of beliefs about money. Psychol Rep 73(3_suppl):1079-1082. doi:10.2466/pr0.1993.73.3f.1079

Kirkpatrick SA, Locke EA (1996) Direct and indirect effects of three core charismatic leadership components on performance and attitudes. J Appl Psychol 81(1):36-51. doi:10.1037/0021-9010.81. 1.36

Knecht S, Dräger B, Deppe M, Bobe L, Lohmann H, Flöel A, Ringelstein E-B, Henningsen H (2000) Handedness and hemispheric language dominance in healthy humans. Brain 123(12):2512-2518. doi:10.1093/brain/123.12.2512

Kohls G, Perino MT, Taylor JM, Madva EN, Cayless SJ, Troiani V, Price E, Faja S, Herrington JD, Schultz RT (2013) The nucleus accumbens is involved in both the pursuit of social reward and the avoidance of social punishment. Neuropsychologia 51(11):2062-2069. doi:10.1016/j. neuropsychologia.2013.07.020

Kross E, Davidson M, Weber J, Ochsner K (2009) Coping with emotions past: the neural bases of regulating affect associated with negative autobiographical memories. Biol Psychiatry 65(5):361-366. doi:10.1016/j.biopsych.2008.10.019 
Lacey S, Hagtvedt H, Patrick VM, Anderson A, Stilla R, Deshpande G, Hu X, Sato JR, Reddy S, Sathian K (2011) Art for reward's sake: visual art recruits the ventral striatum. Neuroimage 55(1):420-433. doi:10.1016/j.neuroimage.2010.11.027

Latham GP, Pinder CC (2005) Work motivation theory and research at the dawn of the twenty-first century. Annu Rev Psychol 56:485-516. doi:10.1146/annurev.psych.55.090902.142105

Leary MR, Cottrell CA, Phillips M (2001) Deconfounding the effects of dominance and social acceptance on self-esteem. J Pers Soc Psychol 81(5):898-909. doi:10.1037/0022-3514.81.5.898

Lee N, Chamberlain L (2007) Neuroimaging and psychophysiological measurement in organizational research: an agenda for research in organizational cognitive neuroscience. Ann N Y Acad Sci 1118:18-42. doi:10.1196/annals.1412.003

Leibenluft E, Gobbini MI, Harrison T, Haxby JV (2004) Mothers' neural activation in response to pictures of their children and other children. Biol Psychiatry 56(4):225-232. doi:10.1016/j.biopsych. 2004.05.017

Lewis KM (2000) When leaders display emotion: how followers respond to negative emotional expression of male and female leaders. J Organ Behav 21(2):221-234. doi:10.1002/(SICI)10991379(200003)21:2<221:AID-JOB36>3.0.CO;2-0

Lilly JD, Duffy JA, Virick M (2006) A gender-sensitive study of McClelland's needs, stress, and turnover intent with work-family conflict. Women Manag Rev 21(8):662-680. doi:10.1108/ 09649420610712045

Lin H-F (2007) Effects of extrinsic and intrinsic motivation on employee knowledge sharing intentions. J Inf Sci 33(2):135-149. doi:10.1177/0165551506068174

Lin A, Adolphs R, Rangel A (2012) Social and monetary reward learning engage overlapping neural substrates. Soc Cogn Affect Neurosci 7(3):274-281. doi:10.1093/scan/nsr006

Liu X, Hairston J, Schrier M, Fan J (2011) Common and distinct networks underlying reward valence and processing stages: a meta-analysis of functional neuroimaging studies. Neurosci Biobehav Rev 35(5):1219-1236. doi:10.1016/j.neubiorev.2010.12.012

Locke EA, Latham GP (2002) Building a practically useful theory of goal setting and task motivation: a 35-year odyssey. Am Psychol 57(9):705-717. doi:10.1037/0003-066X.57.9.705

Locke EA, Latham GP (2004) What should we do about motivation theory? Six recommendations for the twenty-first century. Acad Manag Rev 29(3):388-403. doi:10.5465/AMR.2004.13670974

Lutz A, Nassehi A, Bao Y, Poppel E, Sztrokay A, Reiser M, Fehse K, Gutyrchik E (2013) Neurocognitive processing of body representations in artistic and photographic images. Neuroimage 66:288-292. doi:10.1016/j.neuroimage.2012.10.067

Madden GJ, Begotka AM, Raiff BR, Kastern LL (2003) Delay discounting of real and hypothetical rewards. Exp Clin Psychopharm 11(2):139-145. doi:10.1037/1064-1297.11.2.139

Madden GJ, Raiff BR, Lagorio CH, Begotka AM, Mueller AM, Hehli DJ, Wegener AA (2004) Delay discounting of potentially real and hypothetical rewards: II. Between- and within-subject comparisons. Exp Clin Psychopharm 12(4):251-261. doi:10.1037/1064-1297.12.4.251

Magee JC, Galinsky AD (2008) Social hierarchy: the self-reinforcing nature of power and status. Acad Manag Ann 2(1):351-398. doi:10.1080/19416520802211628

Maier NRF (1955) Psychology in industry, 2nd edn. Houghton Mifflin, Boston

Maldjian JA, Laurienti PJ, Kraft RA, Burdette JH (2003) An automated method for neuroanatomic and cytoarchitectonic atlas-based interrogation of fMRI data sets. Neuroimage 19(3):1233-1239. doi:10. 1016/S1053-8119(03)00169-1

Marsh AA, Blair KS, Vythilingam M, Busis S, Blair RJR (2007) Response options and expectations of reward in decision-making: the differential roles of dorsal and rostral anterior cingulate cortex. Neuroimage 35(2):979-988. doi:10.1016/j.neuroimage.2006.11.044

Maslow AH (1943) A theory of human motivation. Psychol Rev 50(4):370-396. doi:10.1037/h0054346

Massenberg A-C, Spurk D, Kauffeld S (2015) Social support at the workplace, motivation to transfer and training transfer: a multilevel indirect effects model. Int J Train Dev 19(3):161-178. doi:10.1111/ ijtd. 12054

McClelland DC (1957) Community development and the nature of human motivation: some implications of recent research. C, 57-35. Center for International Studies, Massachusetts Institute of Technology, Cambridge

McClelland DC (1976) The achieving society. Irvington Publishers, New York

McClelland DC (1985) How motives, skills, and values determine what people do. Am Psychol 40(7):812-825. doi:10.1037/0003-066X.40.7.812

McClelland DC (1987) Human motivation. Cambridge University Press, Cambridge 
McClelland DC (1991) The personal value questionnaire. McBer \& Co., Boston

McClelland DC, Burnham DH (2008) Power is the great motivator. Harvard business review classics. Harvard Business Press, Boston

McClelland DC, Steele RS (1973) Human motivation: a book of readings. General Learning Press, Morristown

McClelland DC, Atkinson JW, Clark RA, Lowell EL (1953) The achieving motive. Appleton Century Crofts, New York

McNeese-Smith DK (1999) The relationship between managerial motivation, leadership, nurse outcomes and patient satisfaction. J Org Behav 20(2):243-259. doi:10.1002/(SICI)1099-1379(199903)20: 2<243:AID-JOB888>3.0.CO;2-2

Mitterschiffthaler MT, Fu CHY, Dalton JA, Andrew CM, Williams SCR (2007) A functional MRI study of happy and sad affective states induced by classical music. Hum Brain Mapp 28(11):1150-1162. doi:10.1002/hbm.20337

Mizuno K, Tanaka M, Ishii A, Tanabe HC, Onoe H, Sadato N, Watanabe Y (2008) The neural basis of academic achievement motivation. Neuroimage 42(1):369-378. doi:10.1016/j.neuroimage.2008.04. 253

Mourão-Miranda J, Volchan E, Moll J, De Oliveira-Souza R, Oliveira L, Bramati I, Gattass R, Pessoa L (2003) Contributions of stimulus valence and arousal to visual activation during emotional perception. Neuroimage 20(4):1955-1963. doi:10.1016/j.neuroimage.2003.08.011

Nichols T, Brett M, Andersson J, Wager T, Poline J-B (2005) Valid conjunction inference with the minimum statistic. Neuroimage 25(3):653-660. doi:10.1016/j.neuroimage.2004.12.005

O'Cass A, McEwen H (2004) Exploring consumer status and conspicuous consumption. J Consum Behav 4(1):25-39. doi:10.1002/cb.155

Ochsner KN, Lieberman MD (2001) The emergence of social cognitive neuroscience. Am Psychol 56(9):717-734. doi:10.1037/0003-066X.56.9.717

Pauling L, Coryell CD (1936) The magnetic properties and structure of hemoglobin, oxyhemoglobin and carbonmonoxyhemoglobin. Proc Natl Acad Sci USA 22(4):210-216. doi:10.1073/pnas.22.4.210

Peters T, Ghadiri A (2011) Neuroleadership - Grundlagen, Konzepte, Beispiele: Erkenntnisse der Neurowissenschaften für die Mitarbeiterführung. Gabler Verlag/Springer Fachmedien Wiesbaden GmbH Wiesbaden, Wiesbaden

Pfeiffer UJ, Schilbach L, Timmermans B, Kuzmanovic B, Georgescu AL, Bente G, Vogeley K (2014) Why we interact: on the functional role of the striatum in the subjective experience of social interaction. Neuroimage 101:124-137. doi:10.1016/j.neuroimage.2014.06.061

Pinder CC (2008) Work motivation in organizational behavior, 2nd edn. Psychology Press, New York

Poldrack RA, Mumford JA, Nichols TE (2011) Handbook of functional MRI data analysis. Cambridge University Press, Cambridge

Quirin M, Meyer F, Heise N, Kuhl J, Küstermann E, Strüber D, Cacioppo JT (2013) Neural correlates of social motivation: an fMRI study on power versus affiliation. Int J Psychophysiol 88(3):289-295. doi:10.1016/j.ijpsycho.2012.07.003

Reimann M, Weber B (eds) (2011) Neuroökonomie: Grundlagen, Methoden, Anwendungen, 1. Aufl. Lehrbuch. Gabler, Wiesbaden

Rich BL (2006) Job engagement: construct validation and relationships with job satisfaction, job involvement, and intrinsic motivation. Doctoral dissertation, University of Florida

Rothemund Y, Preuschhof C, Bohner G, Bauknecht H-C, Klingebiel R, Flor H, Klapp BF (2007) Differential activation of the dorsal striatum by high-calorie visual food stimuli in obese individuals. Neuroimage 37(2):410-421. doi:10.1016/j.neuroimage.2007.05.008

Rotshtein P, Malach R, Hadar U, Graif M, Hendler T (2001) Feeling or features: different sensitivity to emotion in high order visual cortex and amygdala. Neuron 32(4):747-757. doi:10.1016/S08966273(01)00513-X

Rustagi D, Engel S, Kosfeld M (2010) Conditional cooperation and costly monitoring explain success in forest commons management. Science 330(6006):961-965. doi:10.1126/science.1193649

Sandalgaard N, Bukh PN, Poulsen CS (2011) The interaction between motivational disposition and participative budgeting. J Hum Resour Cost Acc 15(1):7-23. doi:10.1108/14013381111125297

Schaefer M, Rumpel F, Sadrieh A, Reimann M, Denke C (2015) Personal involvement is related to increased search motivation and associated with activity in left BA44: a pilot study. Front Hum Neurosci 9:144. doi:10.3389/fnhum.2015.00144

Schneider K, Schmalt H-D (2000) Motivation, 3, überarb. und erw. Aufl. Kohlhammer Standards Psychologie. Basisbuch. Kohlhammer, Stuttgart 
Schönbrodt FD, Gerstenberg FX (2012) An IRT analysis of motive questionnaires: the Unified Motive Scales. J Res Pers 46(6):725-742. doi:10.1016/j.jrp.2012.08.010

Schüler J, Brandstätter V (2013) How basic need satisfaction and dispositional motives interact in predicting flow experience in sport. J Appl Soc Psychol 43(4):687-705. doi:10.1111/j.1559-1816. 2013.01045.x

Schultheiss OC, Wirth MM, Waugh CE, Stanton SJ, Meier EA, Reuter-Lorenz P (2008) Exploring the motivational brain: effects of implicit power motivation on brain activation in response to facial expressions of emotion. Soc Cogn Affect Neurosci 3(4):333-343. doi:10.1093/scan/nsn030

Sescousse G, Barbalat G, Domenech P, Dreher J-C (2013a) Imbalance in the sensitivity to different types of rewards in pathological gambling. Brain 136(Pt 8):2527-2538. doi:10.1093/brain/awt126

Sescousse G, Caldu X, Segura B, Dreher J-C (2013b) Processing of primary and secondary rewards: a quantitative meta-analysis and review of human functional neuroimaging studies. Neurosci Biobehav Rev 37(4):681-696. doi:10.1016/j.neubiorev.2013.02.002

Sharif AM, Irani Z (2012) Supply chain leadership. Int J Prod Econ 140(1):57-68. doi:10.1016/j.ijpe. 2012.01.041

Small DM, Zatorre RJ, Dagher A, Evans AC, Jones-Gotman M (2001) Changes in brain activity related to eating chocolate: from pleasure to aversion. Brain 124(9):1720-1733. doi:10.1093/brain/124.9.1720

Smith DV, Hayden BY, Truong T-K, Song AW, Platt ML, Huettel SA (2010) Distinct value signals in anterior and posterior ventromedial prefrontal cortex. J Neurosci 30(7):2490-2495. doi:10.1523/ JNEUROSCI.3319-09.2010

Spence JT, Pred RS, Helmreich RL (1989) Achievement strivings, scholastic aptitude, and academic performance: a follow-up to "Impatience versus achievement strivings in the type A pattern". J Appl Psychol 74(1):176-178. doi:10.1037/0021-9010.74.1.176

Spreckelmeyer KN, Krach S, Kohls G, Rademacher L, Irmak A, Konrad K, Kircher T, Gründer G (2009) Anticipation of monetary and social reward differently activates mesolimbic brain structures in men and women. Soc Cogn Affect Neurosci 4(2):158-165. doi:10.1093/scan/nsn051

Stanley DA (2016) Getting to know you: general and specific neural computations for learning about people. Soc Cogn Affect Neurosci 11(4):525-536. doi:10.1093/scan/nsv145

Steers RM, Mowday RT, Shapiro DL (2004) The future of work motivation theory. Acad Manage Rev 29(3):379-387. doi:10.5465/AMR.2004.13670978

Sung Y, Choi SM, Ahn H, Song Y-A (2015) Dimensions of luxury brand personality: scale development and validation. Psychol Mark 32(1):121-132. doi:10.1002/mar.20767

Tang TL-P (1995) The development of a short money ethic scale: attitudes toward money and pay satisfaction revisited. Pers Individ Differ 19(6):809-816. doi:10.1016/S0191-8869(95)00133-6

Thye SR (2000) A status value theory of power in exchange relations. Am Sociol Rev 65(3):407-432. doi: $10.2307 / 2657464$

Truong Y, McColl R (2011) Intrinsic motivations, self-esteem, and luxury goods consumption. J Retail Consum Serv 18(6):555-561. doi:10.1016/j.jretconser.2011.08.004

Tsukiura T, Cabeza R (2011) Shared brain activity for aesthetic and moral judgments: implications for the beauty-is-good stereotype. Soc Cogn Affect Neurosci 6(1):138-148. doi:10.1093/scan/nsq025

Valle M, Perrewe PL (2016) Do politics perceptions relate to political behaviors? Tests of an implicit assumption and expanded model. Hum Relat 53(3):359-386. doi:10.1177/0018726700533004

Veroff J (1992) Power motivation. In: Smith CP (ed) Motivation and personality: handbook of thematic content analysis. Cambridge University Press, New York, pp 278-285

von Rosenstiel L (1975) Die motivationalen Grundlagen des Verhaltens in Organisationen. Leistung und Zufriedenheit. Duncker \& Humblot, Berlin

Vroom VH (1964) Work and motivation. Wiley, New York

Wiesenfeld BM, Raghuram S, Garud R (2001) Organizational identification among virtual workers: the role of need for affiliation and perceived work-based social support. J Manag 27(2):213-229. doi:10. 1177/014920630102700205

Winter DG (1973) The power motive. Free Press, New York

Winter DG, Stewart AJ (1978) The power motive. In: London H, Exner JE (eds) Dimensions of personality. Wiley, New York, pp 391-447

Wong A, Carducci BJ (1991) Sensation seeking and financial risk taking in everyday money matters. J Bus Psychol 5(4):525-530. doi:10.1007/BF01014500 